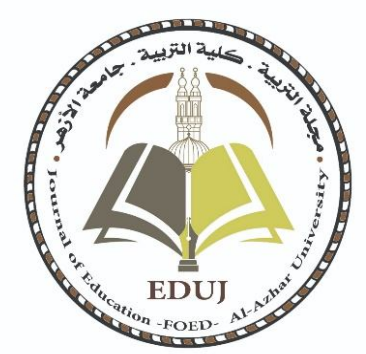

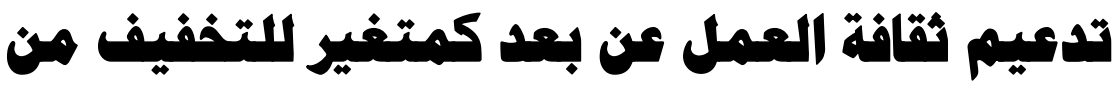 هدة البطالة لدى خريجى الجامعات المصرية
}

\author{
إعداد \\ أ/ عيد إسماعيل أهمود هممد
}

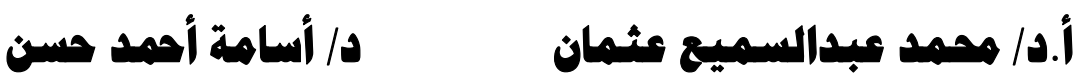
قسم الذدمة الاجتماعية وتنمية المجتمع ـ كلية التربية ـ جامعة الأزهر بالقاهرة 
تذعيم ثقافة العمل عن بعد كمتفير للتخفيف من حدة البطالة لاى المى خريجى الجامعات المصرية

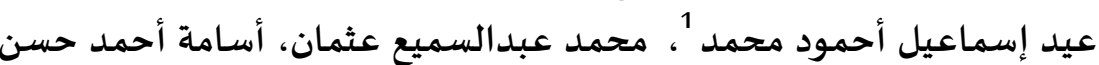

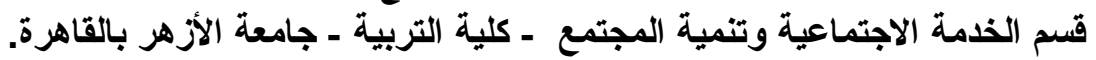

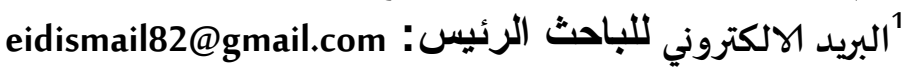

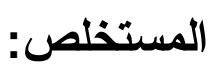

استهدف البحث التعرف على واقع ممارسـة الشباب خريجى الجامعات لنظام العمل

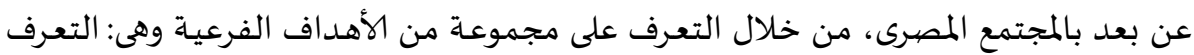
على مستوى وعى الشباب المصرى ومعرفتـا بنظام العمل عن بعدل، وقياس اتجاهـات الشباب

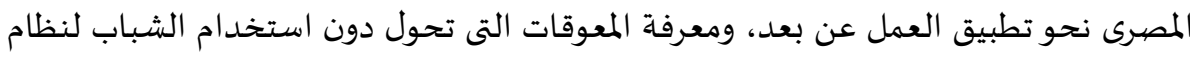

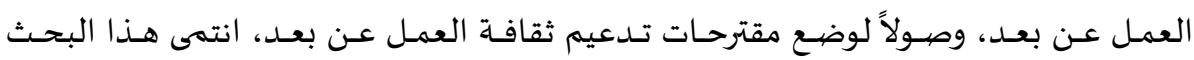

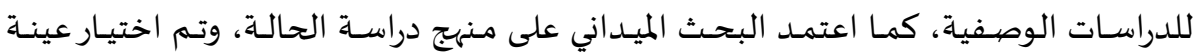

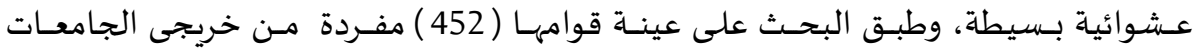

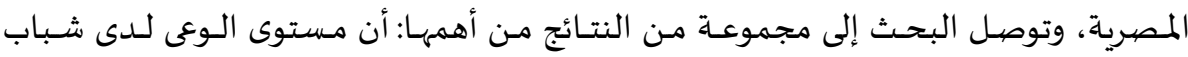

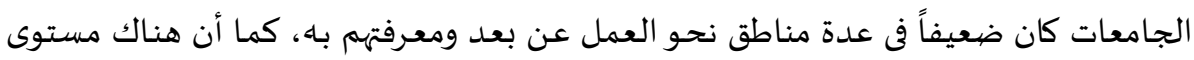

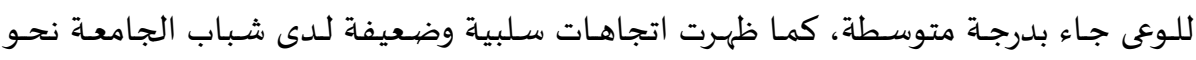
تطبيق العمل عن بعد في بعض المناطق، وأخرى متوسطة ومرتفعة، كما ظهرت معوقات تحول

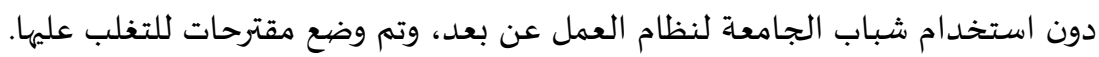
الكلمات المفتاحية: العمل عن بعد، البطالة، خريجى الجامعات المصرية. 


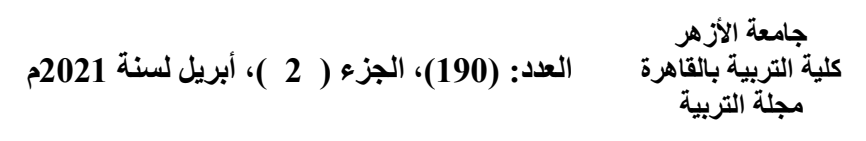

Supporting the Culture of Telework as a Variable to Reduce Unemployment Rate among Egyptian University Graduates

\author{
Eid Ismail Ahmed Mahmoud ${ }^{1}$, Mohamed Abdel Samee Othman, \\ Osama Ahmed Hassan \\ Community Development Specialization, Social Work and \\ Community Development Department, Faculty of Education in \\ Cairo, AlAzhar University \\ ${ }^{1}$ Corresponding author E-mail: eidismail82@gmail.com
}

\begin{abstract}
This research aimed to identify the status-quo of university young graduates' practice of telework system in the Egyptian society by recognizing a set of sub-objectives, represented in identifying the level of Egyptian youth awareness and knowledge of telework system, and measuring the Egyptian youth's attitudes towards the fulfillment of telework. Furthermore, the resesrch aimed at identifying the obstacles which prevent the youth from using the telework system in order to develop some recommendations to support the culture of telework. This research belonged to descriptive studies, and the field of research was based on the case study method. A simple random sample was also selected. The research was administered to a sample of (452) individual graduates of Egyptian universities, and the research developed a set of results, the most important of which are that: the level of awareness among university youth was weak in several areas towards online work and their knowledge. There was also a medium level of awareness, as well as negative weak attitudes among university youth towards the fulfillment of telework in some areas. Furthermore, there were obstacles appeared that prevent university youth from using the telework system and some recommendations were developed to overcome them.
\end{abstract}

Keywords: Telework, Unemployment, Graduates of Egyptian Universities. 


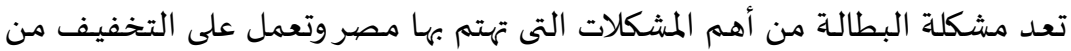

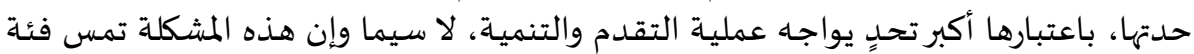

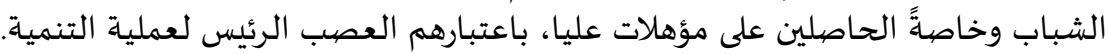

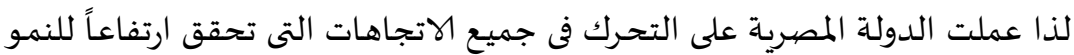

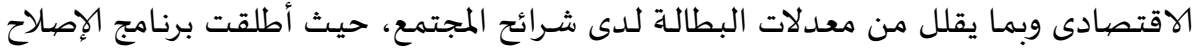

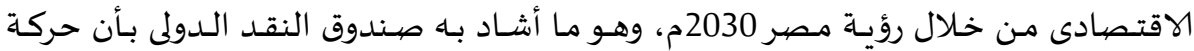

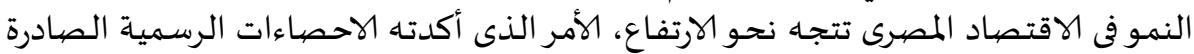

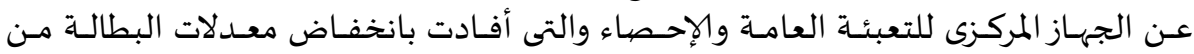

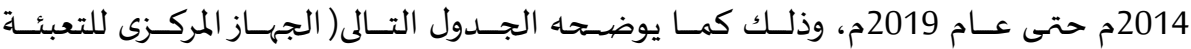
والاحصاء:2019م).

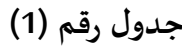

يوضح أعداد المتعطلين عن العمل ومعدلات البطالة بمصر.

\begin{tabular}{|c|c|c|c|c|c|c|}
\hline 2019م & 2018م & 2017م & 2016م & 2015م & 2014م & البيان \\
\hline 2236000 & 2491000 & 3468000 & 3603000 & 3652000 & 3646000 & المتعططلون عن \\
\hline$\% 7,7$ & $\% 8,9$ & $\% 11,8$ & $\% 12,5$ & $\% 12,8$ & $\% 13,0$ & معدل البطالة \\
\hline
\end{tabular}

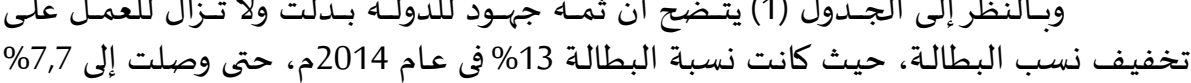

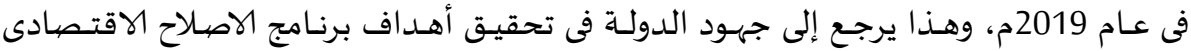

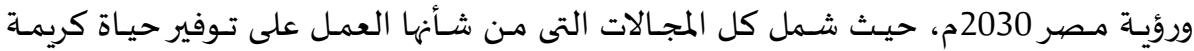

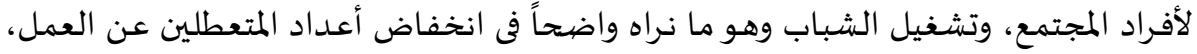

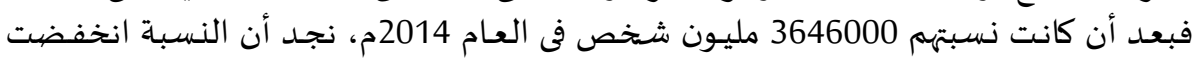

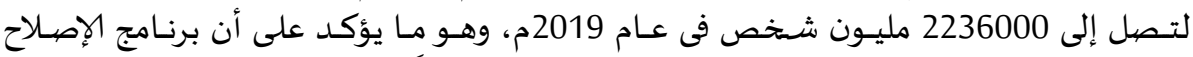

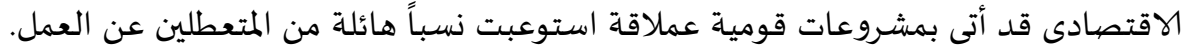

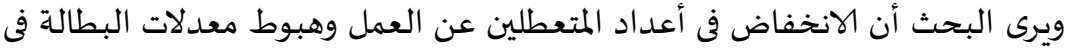

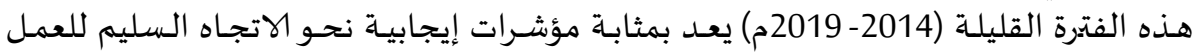

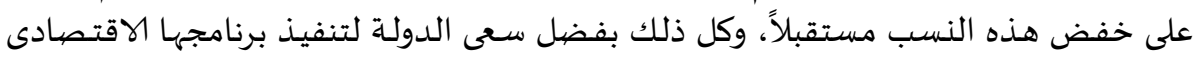
ورؤية مصر 2030م. - 2030.

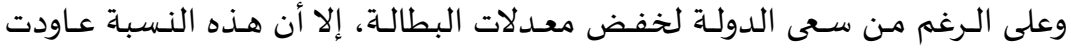

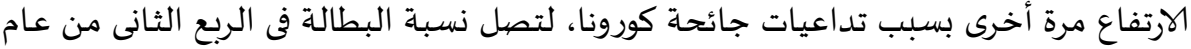

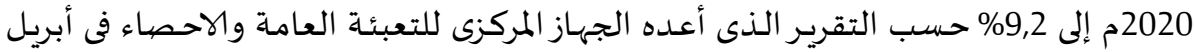

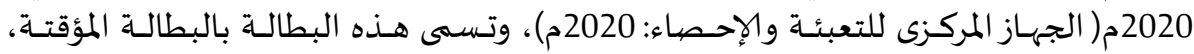

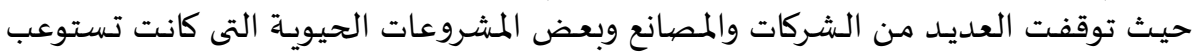

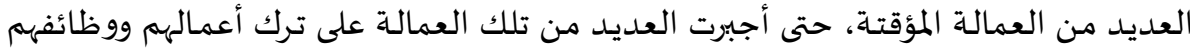




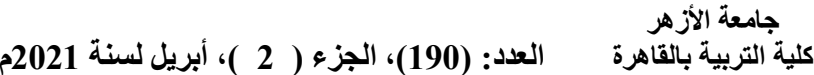

خوفاً على حياتهم وحياة ذويهم، ويرى البحث أن هذه النسبة ستعاود الانخفاض مرة أخرى

$$
\text { بزوال هذه الأزمة. }
$$

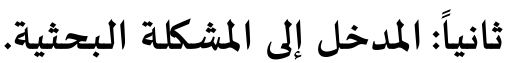

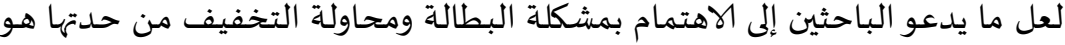

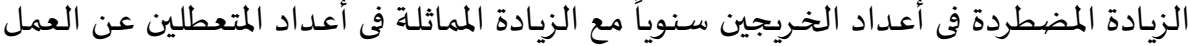

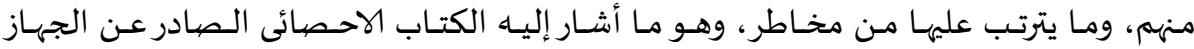

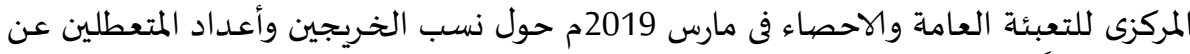

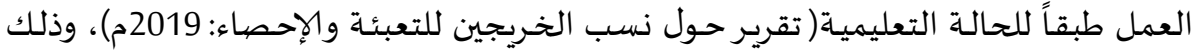

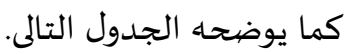

\section{جدول (2)}

يوضح أعداد خريجى التعليم العالى، وأعداد المتعطلون عن العمل وفقاً للحالة التعليمية.

\begin{tabular}{|c|c|c|c|}
\hline معدلات البطالة طبقاً للحالة & 2018م & 2017م & سنة التخرج \\
\hline $1,460,000$ & 85,000 & 98,636 & ختريجى فوق والمعاهد \\
\hline المعدلات تشمل الجامعات وما & 406,000 & 367,549 & الحكومية والززهر \\
\hline $11,778,000$ & 24,000 & 22,310 & الجامعات الخاصة \\
\hline 13238000 & 515,000 & 488,495 & الاجمالى \\
\hline
\end{tabular}

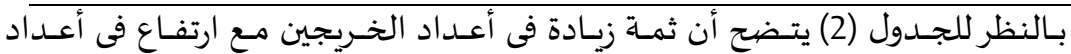

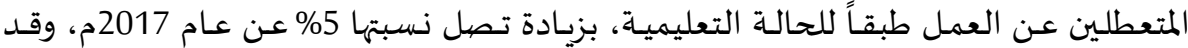

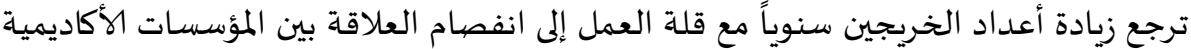

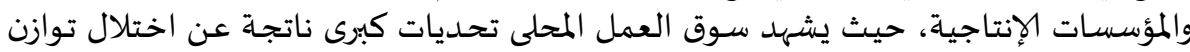

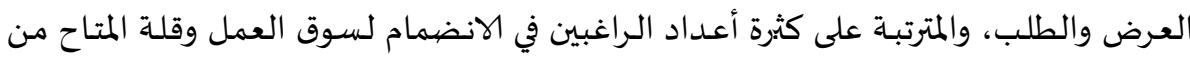

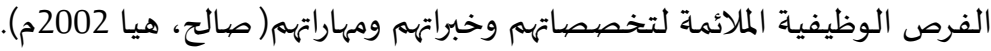

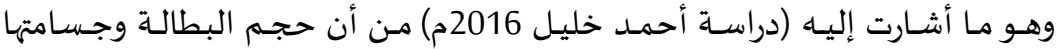

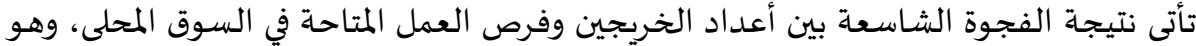

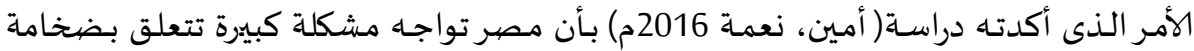

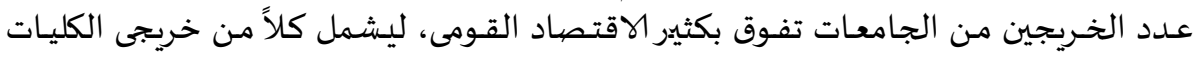




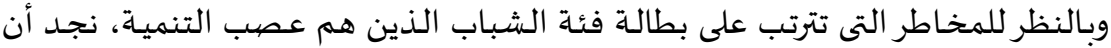

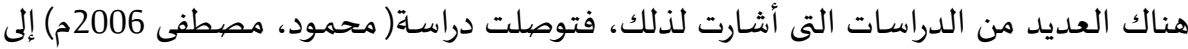

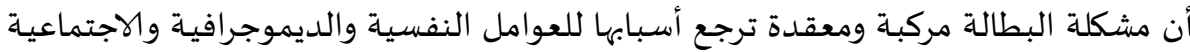

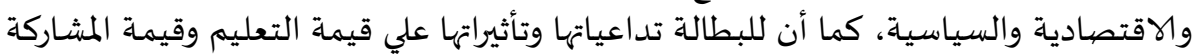

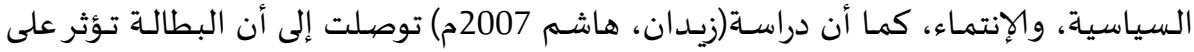

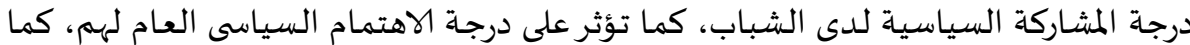
تؤثر على درجة المعرفة السياسية لهم.

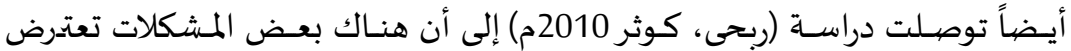

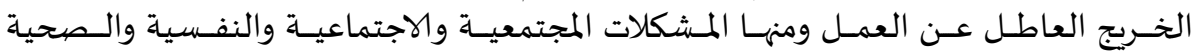

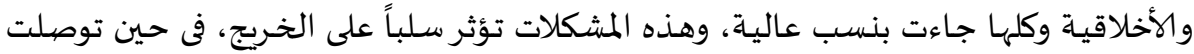

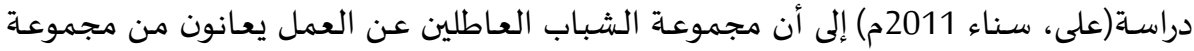

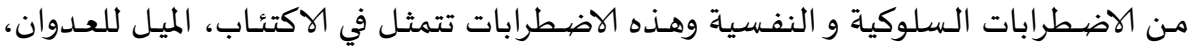

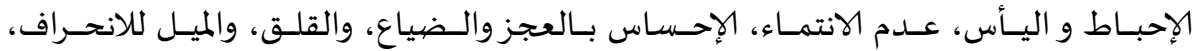

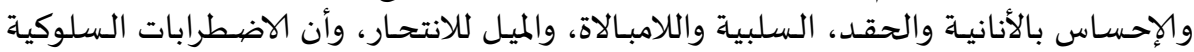

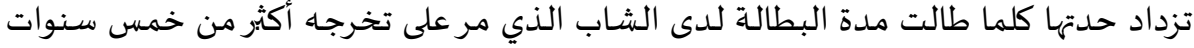

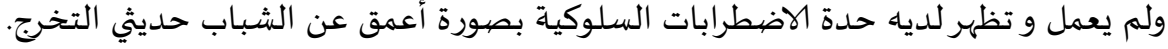

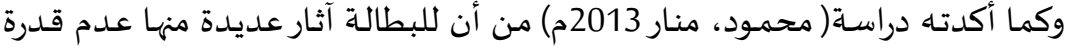

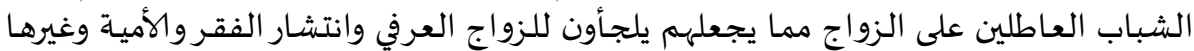

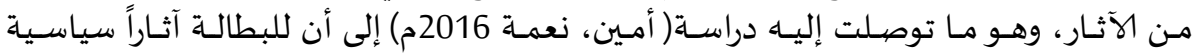

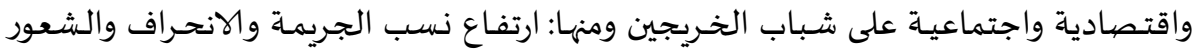

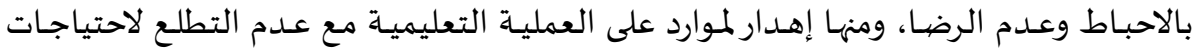

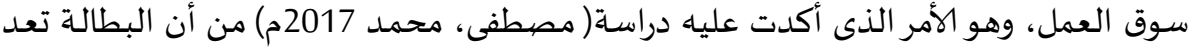

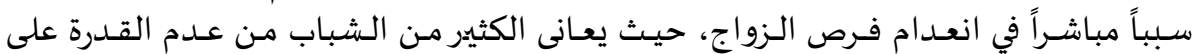

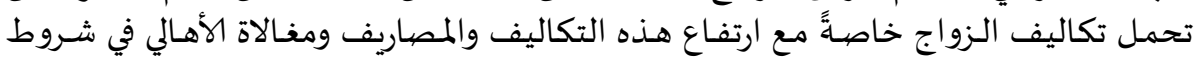

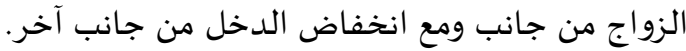

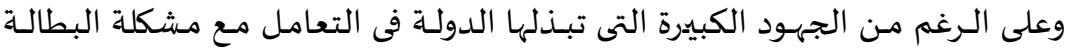

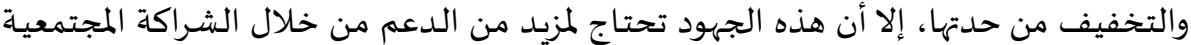

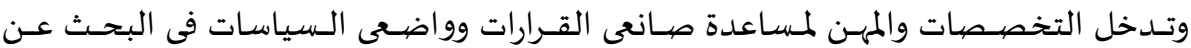

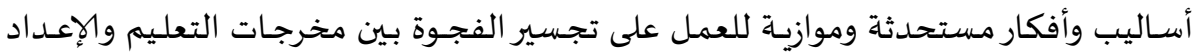
والتأهيل من جهال، وبين جهات التوظيف من من جهاز أخرى.

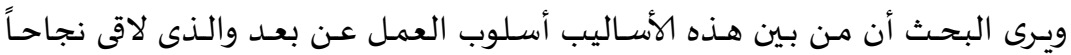

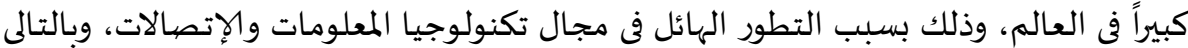

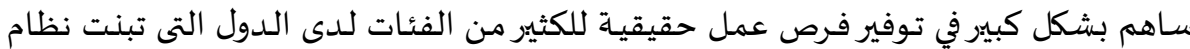

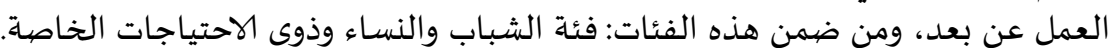

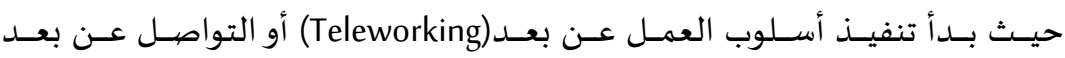
(Telecommuting) 


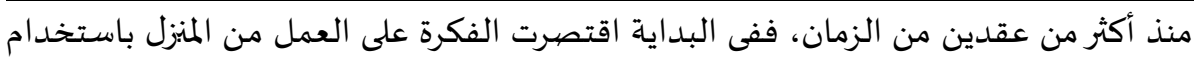

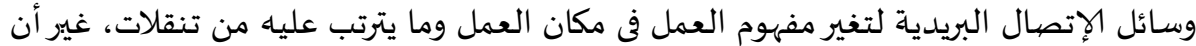

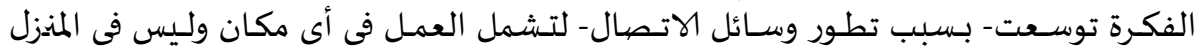

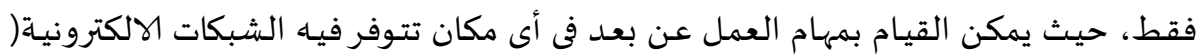

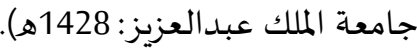

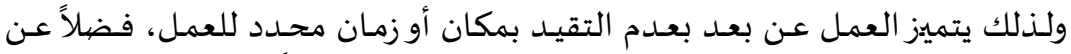

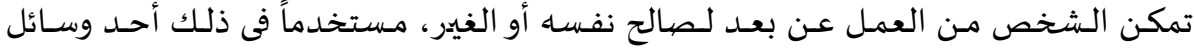
الاتصالات وتكنولوجيا المعلومات (جامعة الملك عبد المبل العزيز: 1428هـ).

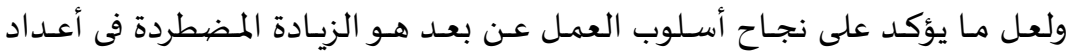

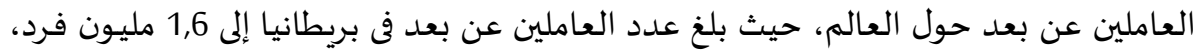

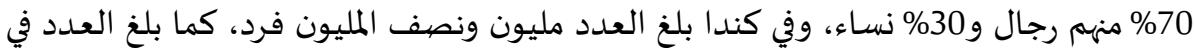

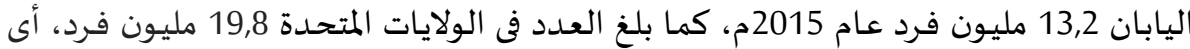

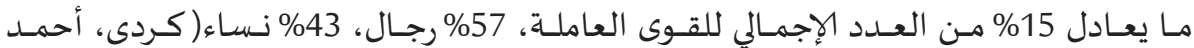

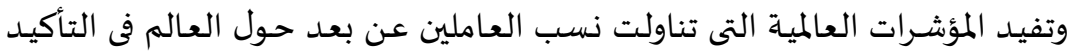

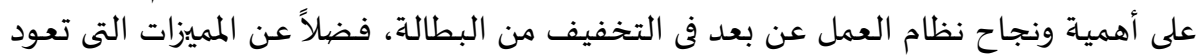

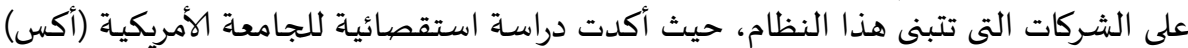

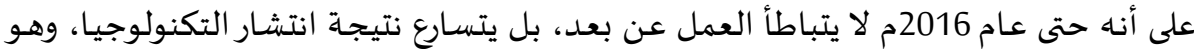

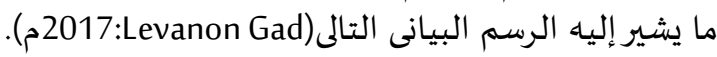

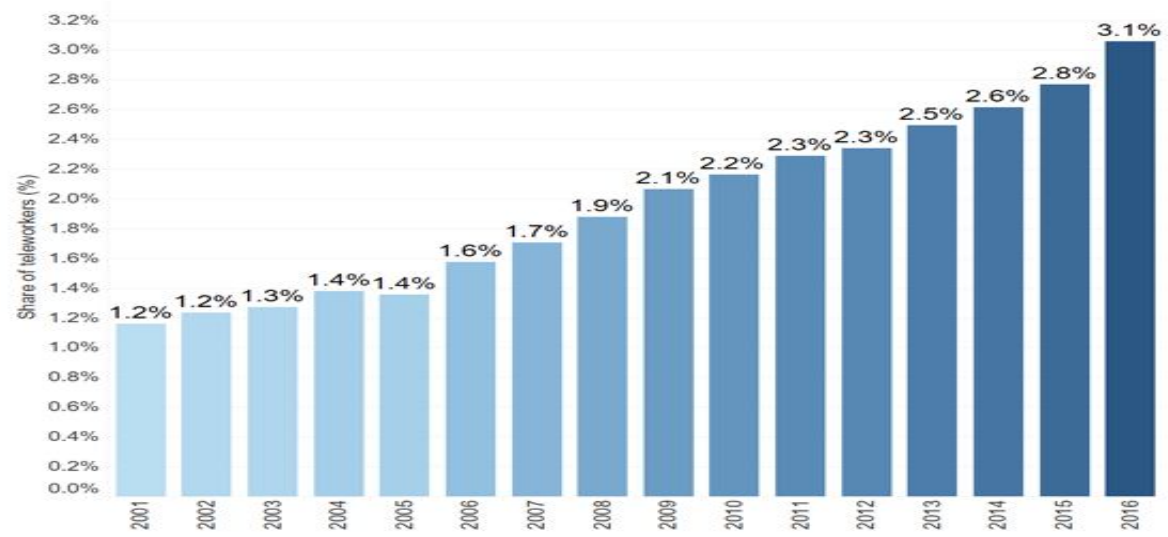

وبالنظر إلى الرسم البيانى السابق يتبين أن أسلوب العمل عن بعدي تعد يتزايد في أمريكا، وهذا

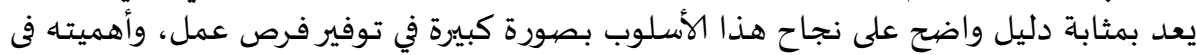

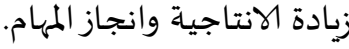


وهو ما أشـارت إليه الدراسة التى أجرتها شركة أميركية متخصصية في اتجاهات العمل والإنتاجية

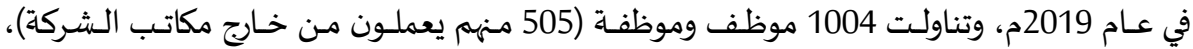
وتوصلت نتائجها إلى أن الذين يعملون عن بعام بعد هم أكثر إنتاجية من الذين يعملون في في مكاري مكاتب الشركة)

دراسة أمريكية: 2020م).

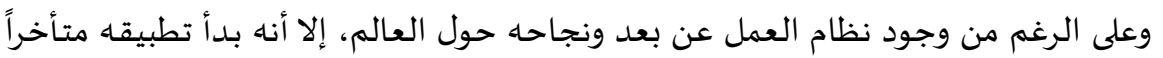

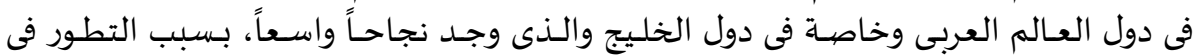

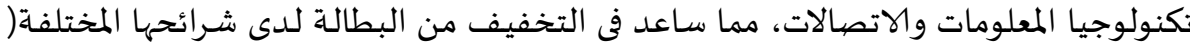

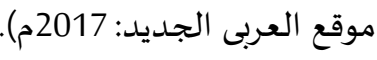

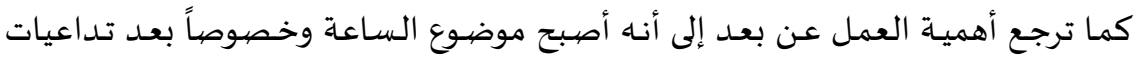

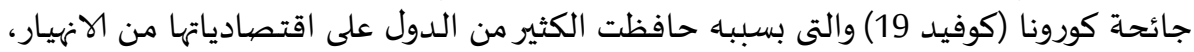
كما حافظت على حياة مواطنيها من انتشار الفيروس.

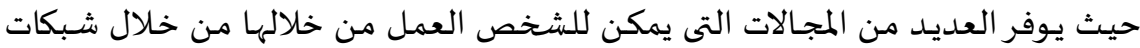

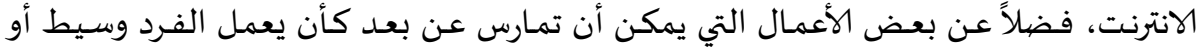

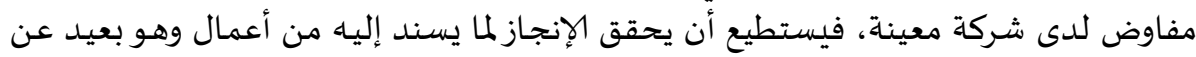

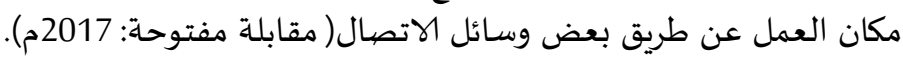

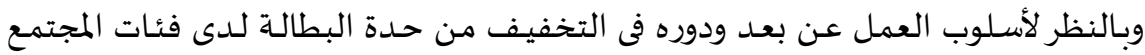

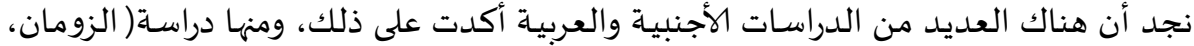

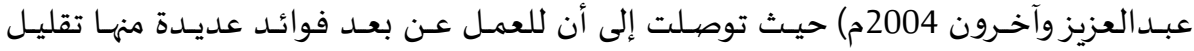

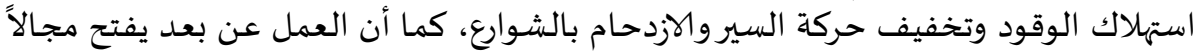

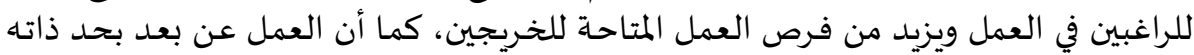

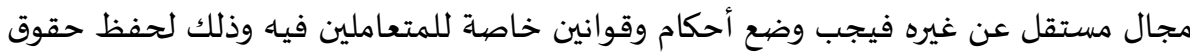

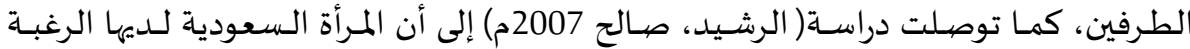

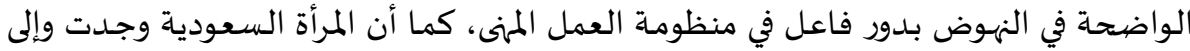

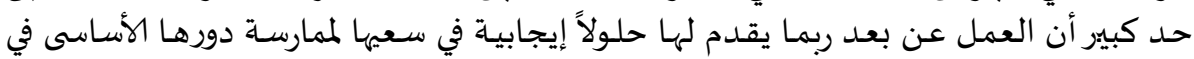
رعاية أسرتها ودورها المرغوب في مزاولة العمل العمل المهنى.

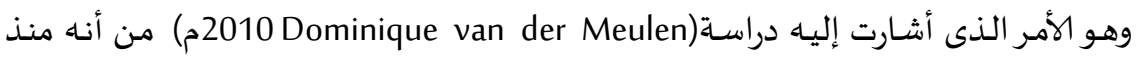

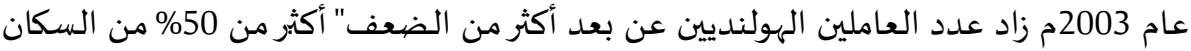

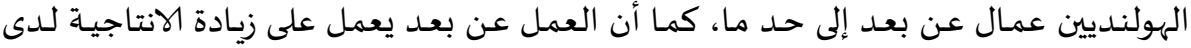

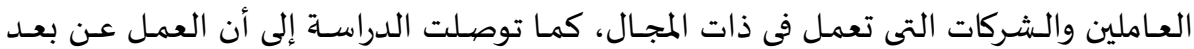

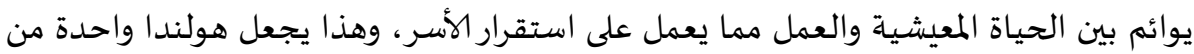

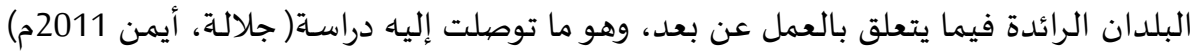

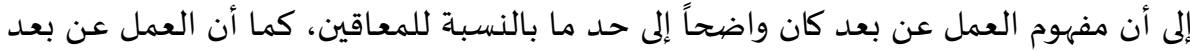

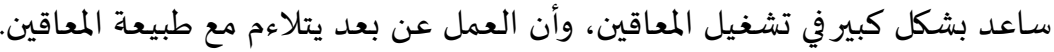

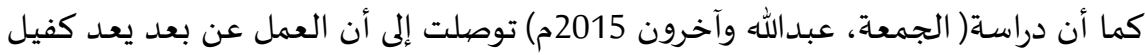

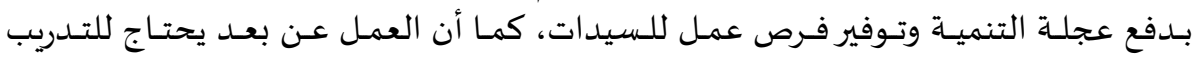

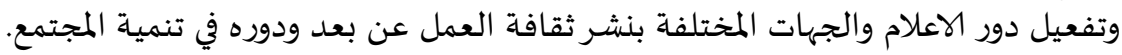




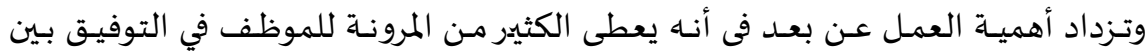

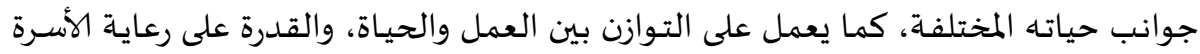

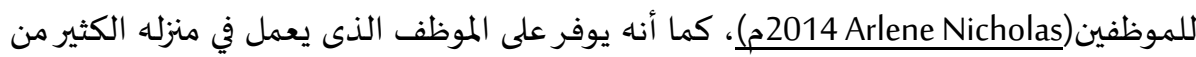

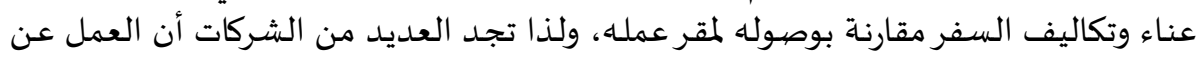

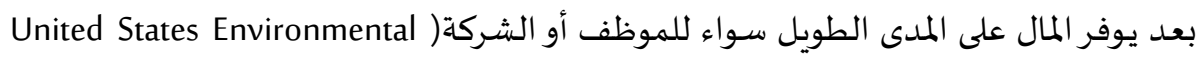

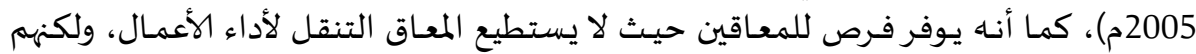

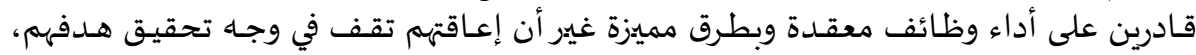

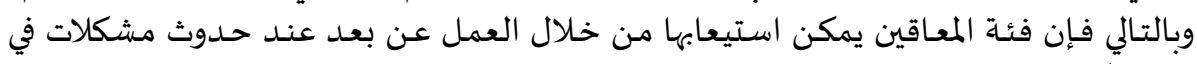

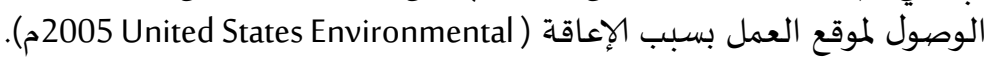

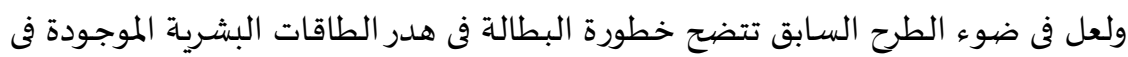

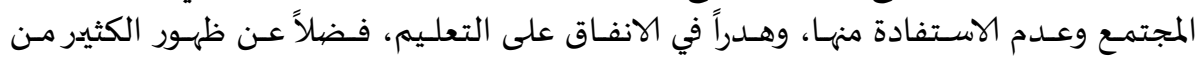

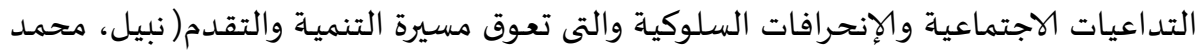

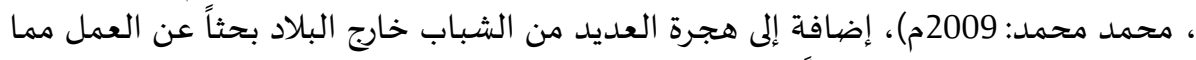

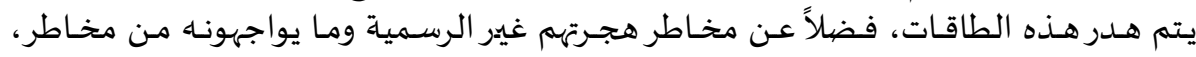

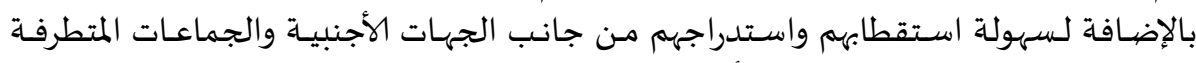

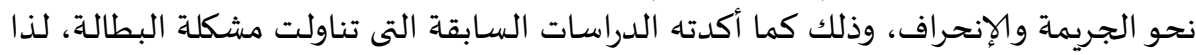

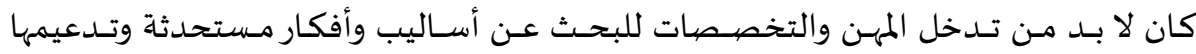
للتخفيف من حدة البطالة، ومن بين هذه التخدي الأساليب أسلوب العمن العمل عن بعد.

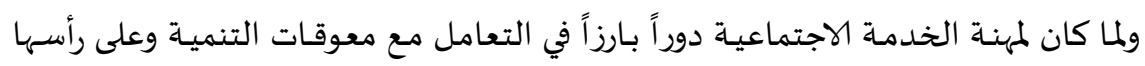

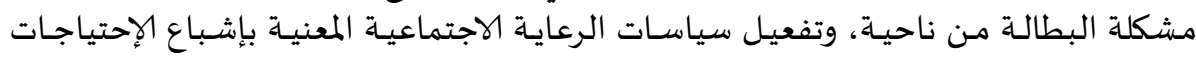

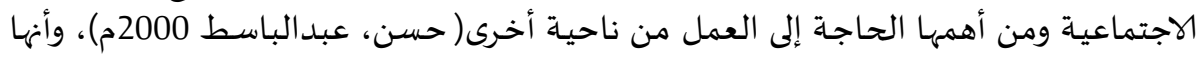

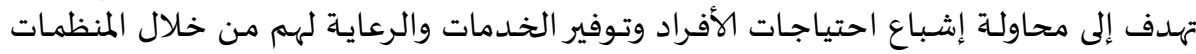
الاجتماعية سواء الحكومية أو الأهلية (خزام، الأفراد منى 2011م) الخدمات.

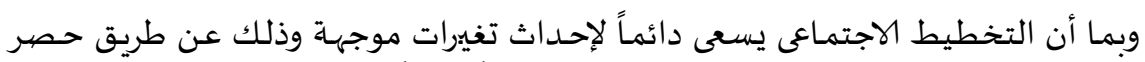

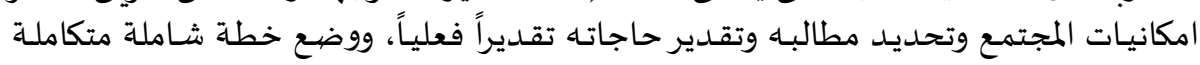

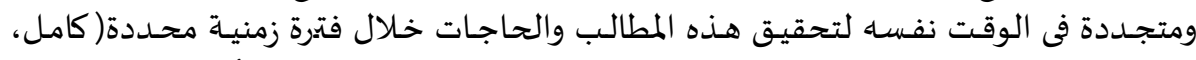

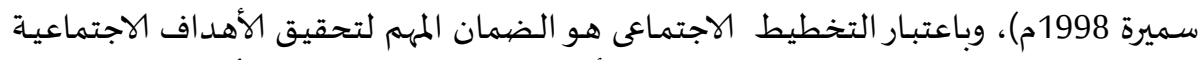

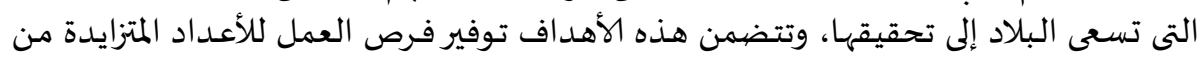

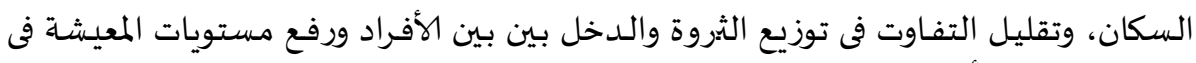
مختلف المناطقى (أبو المعاطى، ماهر: فئ توزيع الثروة 2010م).

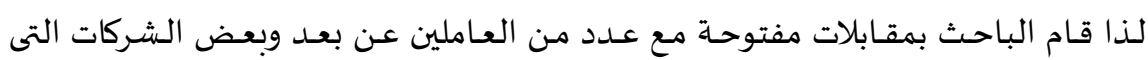

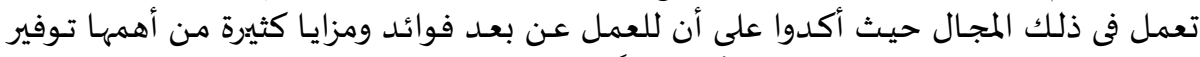

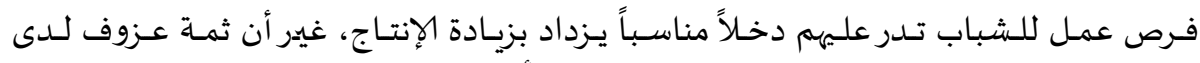

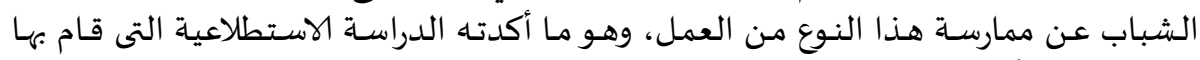

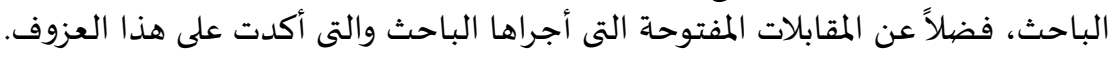




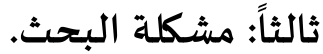

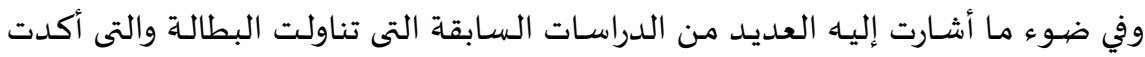

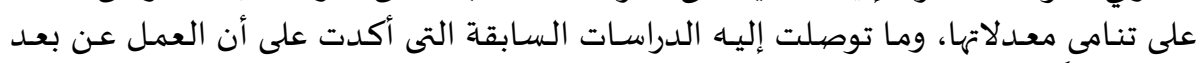

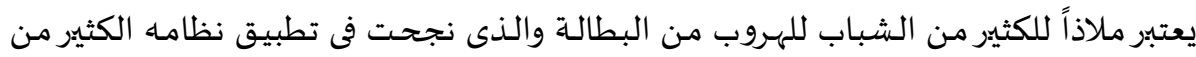

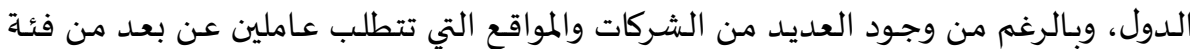

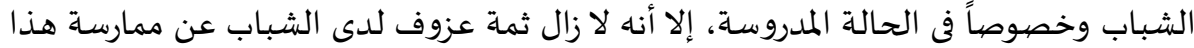

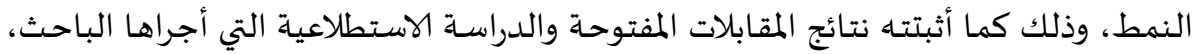

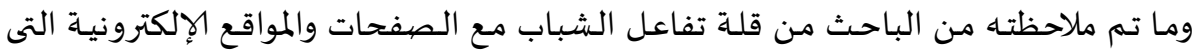

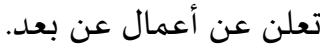

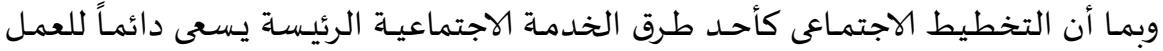

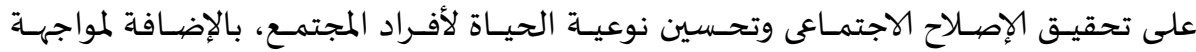

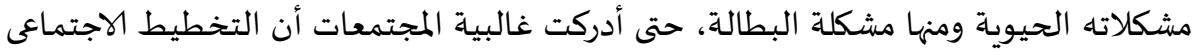

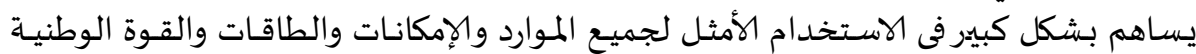

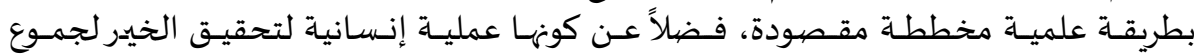

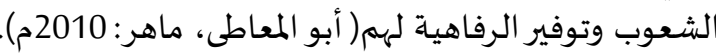

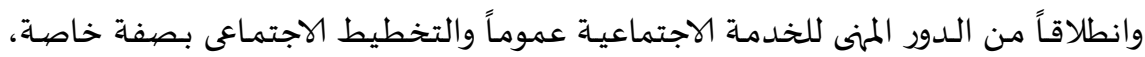

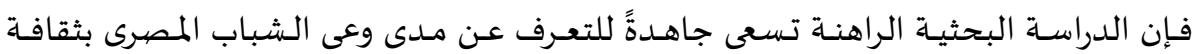

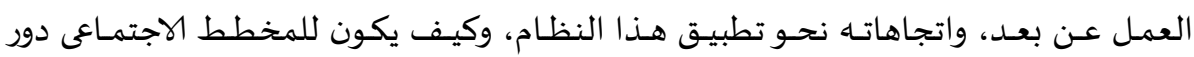

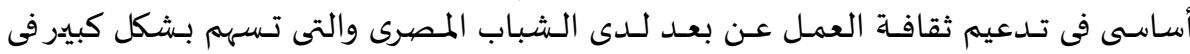
التخفيف من حدة البطالة لديهم. ويمكن صياغة المشكلة البحثية من خلال طرح التساؤلات التالية:

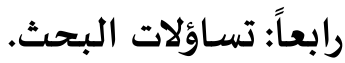
- التساؤل الرئيس:

إلى أى مدىى يمكن تدعيم ثقافة العمل عن بعد للتخفيف من حسدة البطالة لدى خريجى

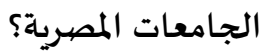

ويتطلب الاجابة عن مجموعة من التساؤلات الفرعية وهى:

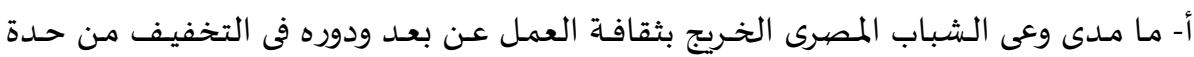

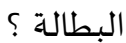
ب- ما اتجاهات الشباب المصرى نحو تطبيق العمل عن بعد؟

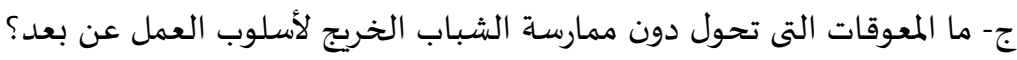

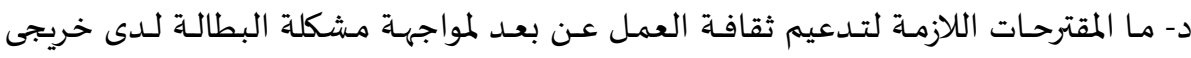

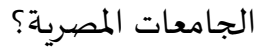




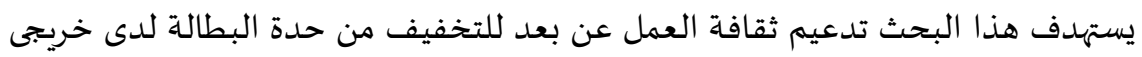

الجامعات المصرية، وينبثق من ذلك الهدف عدة الهدة أهداف فرعية وهى:

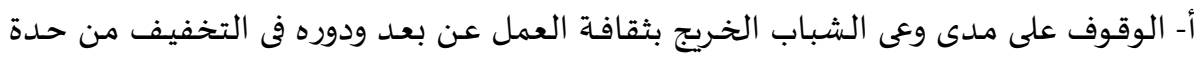

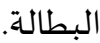

ب- التعرف على اتجاهات الشباب الخريج نحو تطبيق العمل عن بعد.

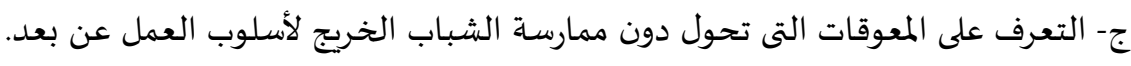

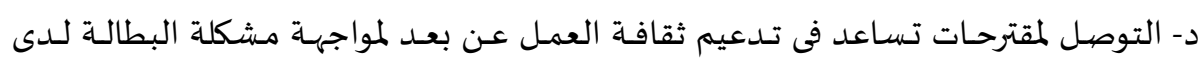
خريجى الجامعات. سادساً: أهمية البحث. البحمات. 1- أأهمية العلمية والنظرية:

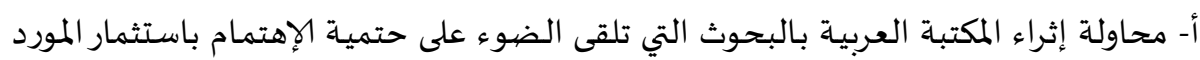

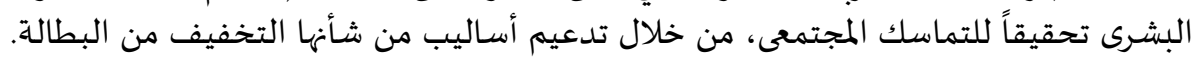

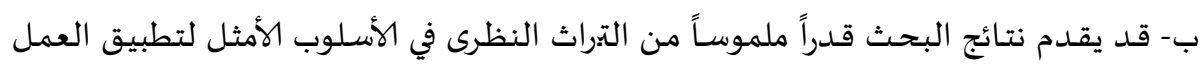
عن بعد من منظور التخطيط الاجتماعى.

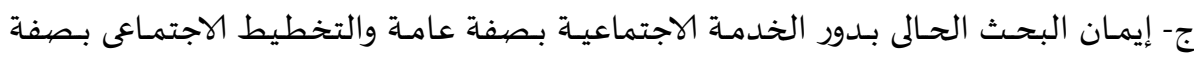

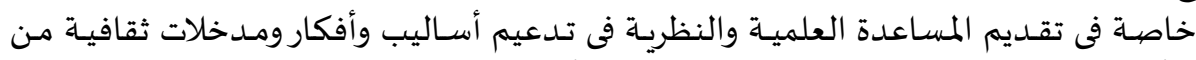

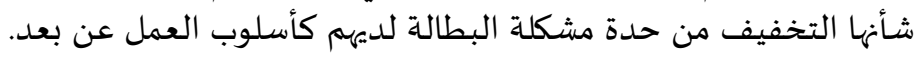

2- أأهمية المهنية والتطبيقية:

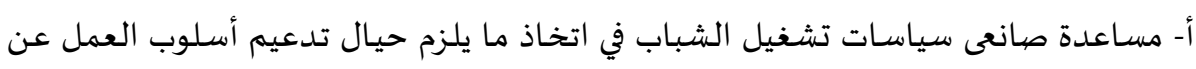

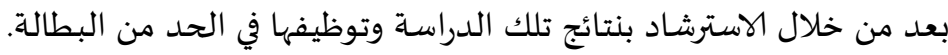

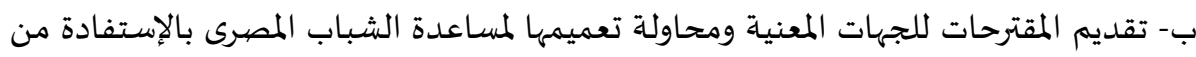
تلك في الحصول على فرصة عمل.

3- 3- الأهمية المجتمعية:

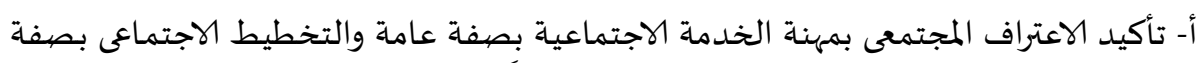

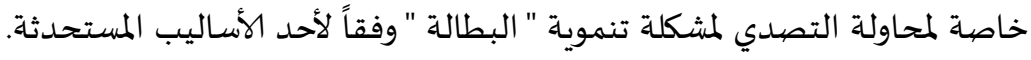
ب- الفائدة التى ستعود على المجتمع والشباب في حالة تدعيم ثقافة العمل عن بعد البهد في إطار

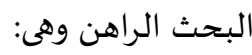


- استثمار الطاقات البشرية الموجودة في المجتمع والاستفادة منها وتوظيفها فيما يسمى بالعمل

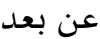

- توفير فرص عمل للشباب تدر عليهم دخلاً مناسباً بدلاً من انتظارهم عملاً رسمياً.

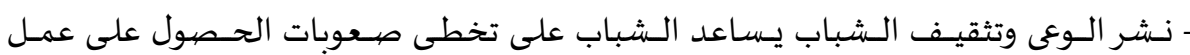

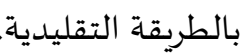

- توفير الوقت والجهد وتكاليف وسائل النقل. - توفيروقت أكبر لرعاية الأسرة ومتطلبات الروابط العائلية. - تحسين نوعية حياة الشباب ووقايتهم من عوامل الانحراف والجريمة.

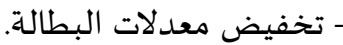
- توفير تكاليف بناء المكاتب وتجهيزها بالنسبة للشركات.

- زيادة الإنتاجية نتيجة لاستخدام التقنية الحديثة. - الحد من هجرة الشباب خارج البلاد والاستفادة منهم فى تنمية مجتمعهم.

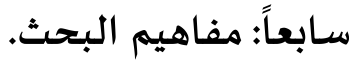

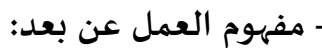

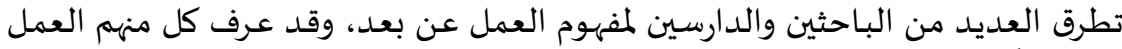

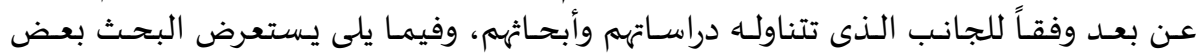

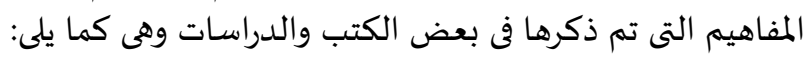

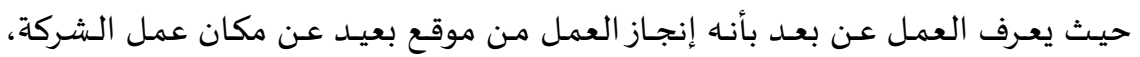

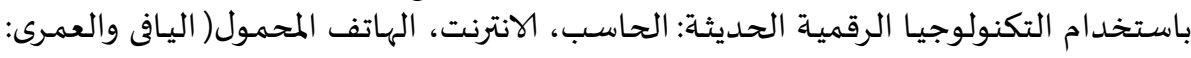

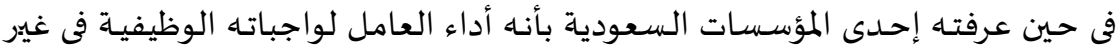

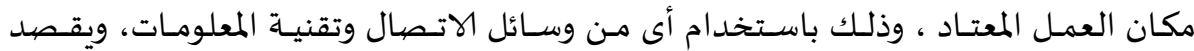

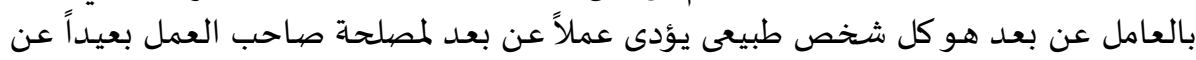

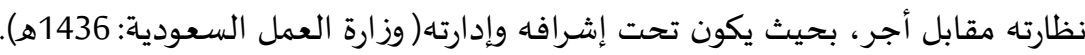

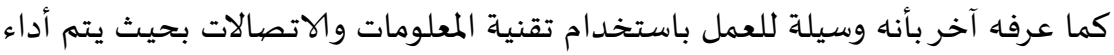

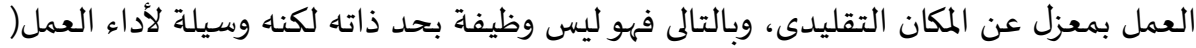

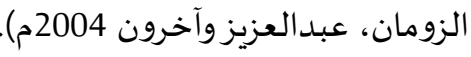
وهناك مصطلحات مرتبطة بالعمل عن بعد ومنها: - العمل من المنزل. - العمل من خلال الانترنت والهاتف. - التسويق الاكتترونى. - العمل المرن. وفى ضوء ما سبق يمكن للبحث أن يعرف العمل عن بعد إجرائياً في إطار الدراسة الراهنة بأنه: 


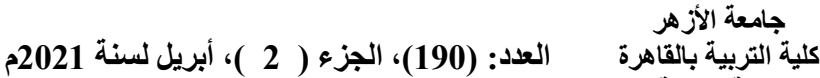 \\ مجلة التربية بالثقاهرة

1- هو أسلوب للقيام بالعمل بعيداً عن مكان المؤسسة دون التقيد بوقت أو مكان محدد.

2- وسيلة للحصول على فرصة عمل حقيقية للخريج العاطل عن العمل.

3- يمكن للشخص العمل عن بعد لحسابه الشخصى أو لحساب الغير.

4- يتم العمل عن بعد من خلال التواصل بوسائل الاتصال المختلفة.

5- يمكن للفرد أن يعمل في مجالات عديدة وفق مهاراته وخبراته.

6- العمل عن بعد يقلل من نسبة البطالة لدى الشباب.

7- للعمل عن بعد علاقة بإنجاز المهام وزيادة الإنتاجية وتقليل تكاليف الإنتاج.

ويقصيد بتدعيم ثقافة العمل عن بعد إجرائياً:

** استثمار المدخلات الثقافية للقوى البشرية الموجودة في المجتمع التي لا تعمل للاستفادة منها

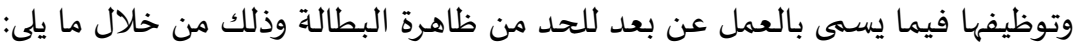

$$
\begin{aligned}
& \text { 1- تدعيم البنية المعرفية للعمل عن بعد لدى الشباب. } \\
& \text { 2- تدعيم البنية المهارية اللازمة للعمل عن بعد لدى الشباب. }
\end{aligned}
$$

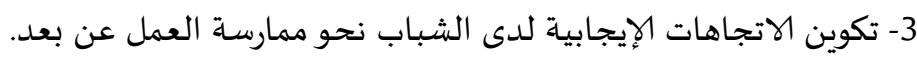

$$
\begin{aligned}
& \text { 4- تزويد الشباب بالخبرات اللازمة لتطبيق العمل عن بعد. }
\end{aligned}
$$

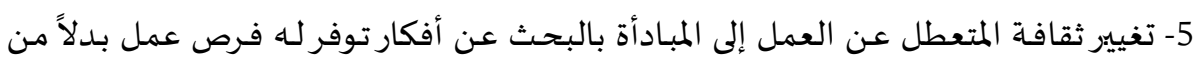
الانتظار.

6- محاولة الإقناع باستخدام المداخل الثقافية بأهمية العمل عن بعد ومدى مساهمته في الحد

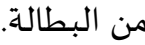

- مفهوم البطالة: - من البطالة

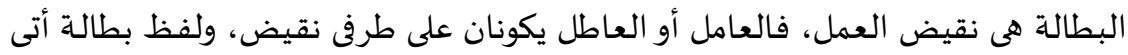

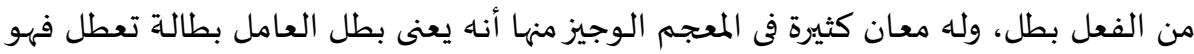

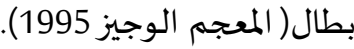

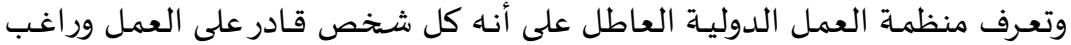

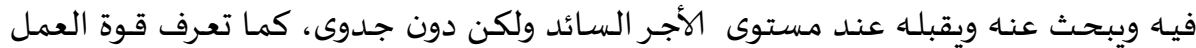

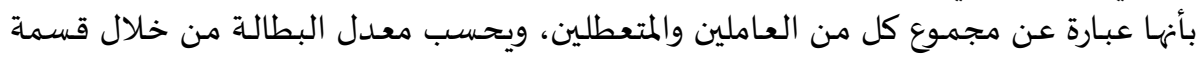

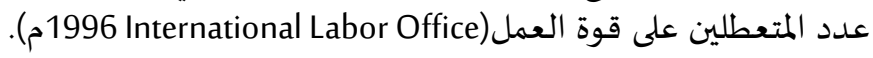
هذا ويمكن تعريف الشباب المتعطل في إطار الدراسة الراهنة اجرائياً كما يلى: 1- الشباب هم خريجى الجامعات بالمجتمع المصرى. 2- مجموعة من الأفراد الذكور والإناث الذين يبحثون عن العمل ولا يجدونه. 
3- لديهم من المهارات ما يؤهلهم للعمل عن بعد.

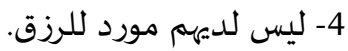

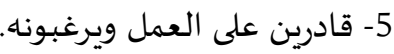

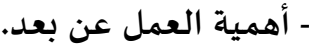

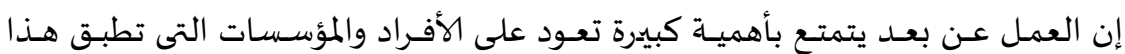

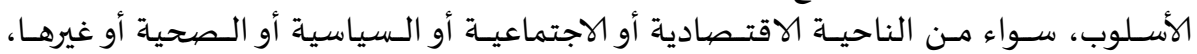

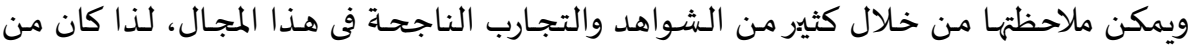

الأهمية بمكان ذكر أهمية العمل عن بعد العند والتى يمكن تناولها في النقاط التالية:

1- 1 - أهمية العمل عن بعد بالنسبة للأفراد:

أ- يعمل على إيجاد التوازن بين العمل والحياة والوقت: حيث يعطى الكثير من المرونة للموظف

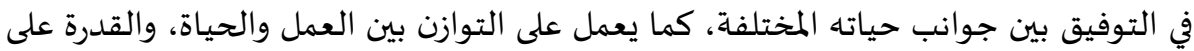

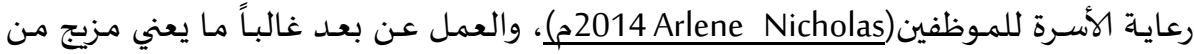

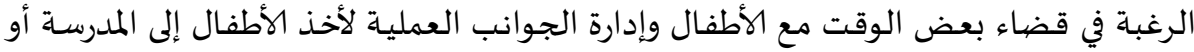

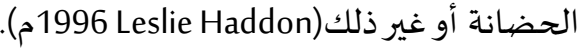

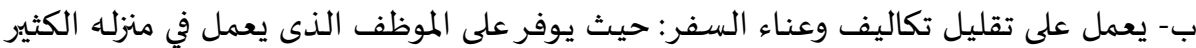

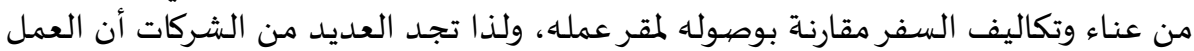

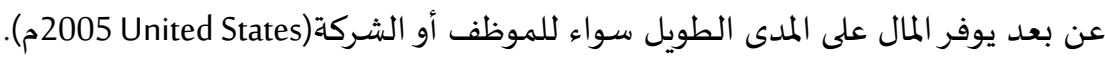

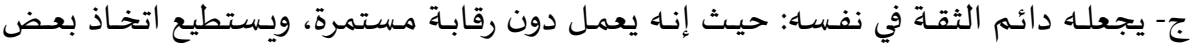

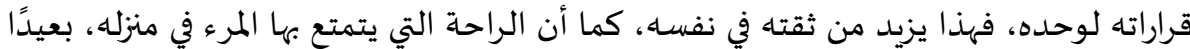

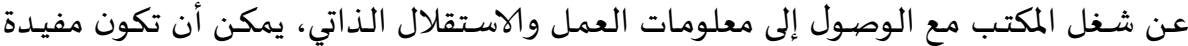

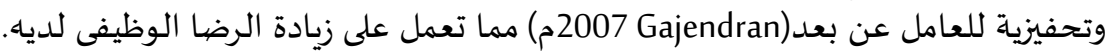

د- يوفر المزيدـ من فرص العمل: وخاصـة للخريجين الذين لا تتوافر لديهم وظائف، وبالتـالي يتم المساعدة في تخفيف نسبة البطالة.

ز- يعمل على توفير فرص عمل للمعاقين: حيث لا يستطيع المعاق التنقل لأداء الأعمال، ولكنهم

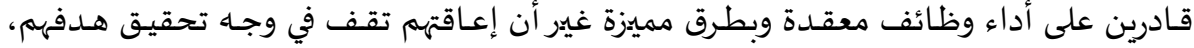

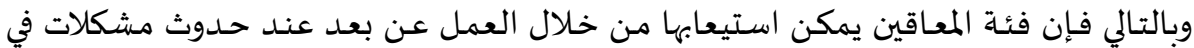

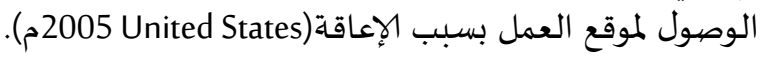

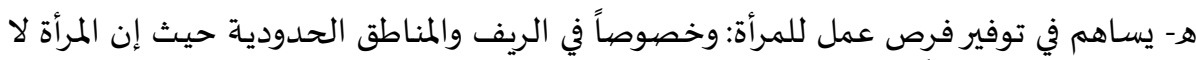

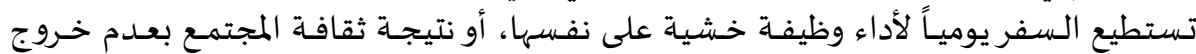

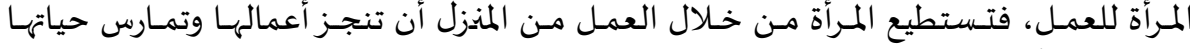
الزوجية والأسرية دون تقصير. 
2- أهمية العمل عن بعد بالنسبة للمؤسسات:

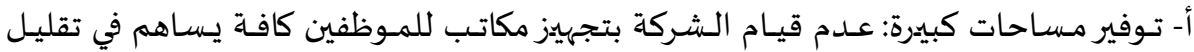

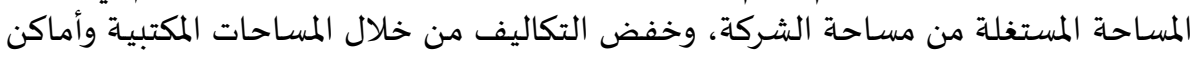

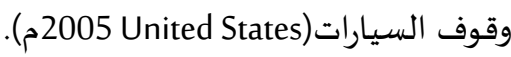

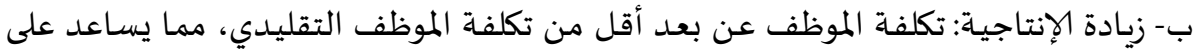

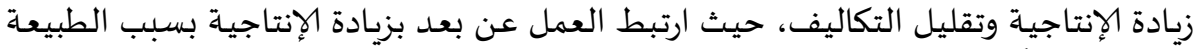

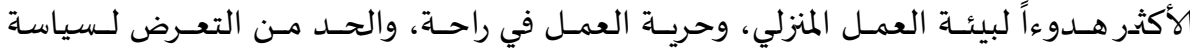

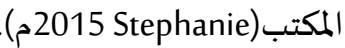

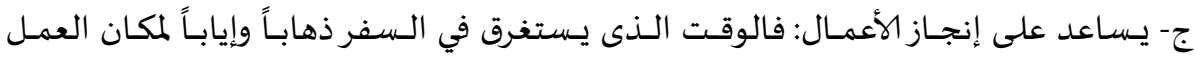

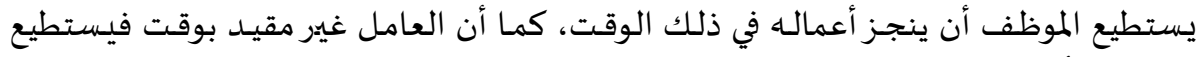

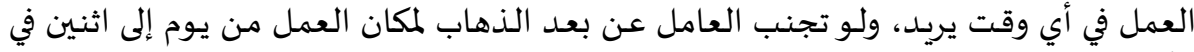

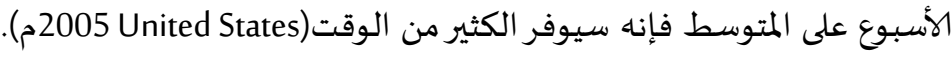

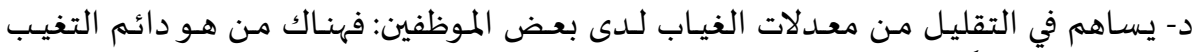

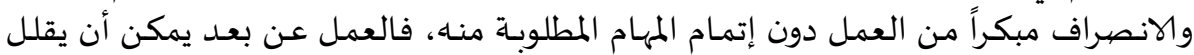

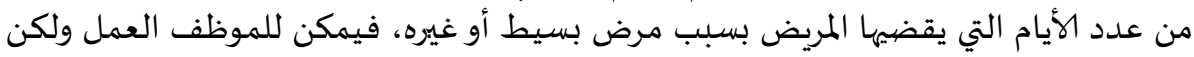
يبقى في المنزل(2011 Department of Broadbandم).

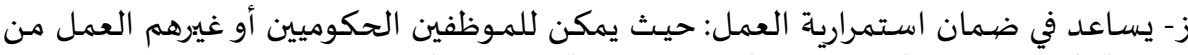
المنزل أو أي مكان آخر أثناء سوء الأحوال الجوية أو الكوارث أو تفشي الوباء.

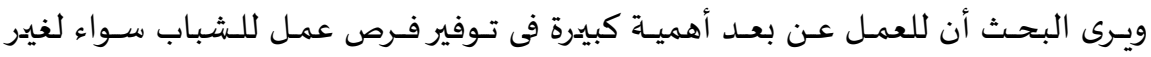

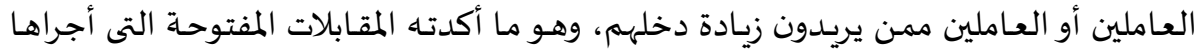

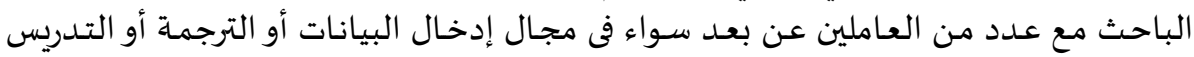

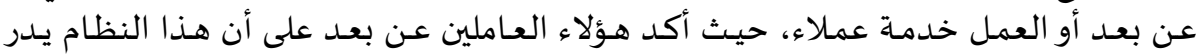

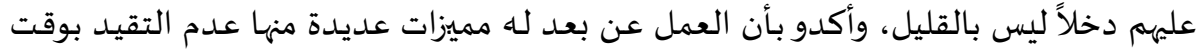
أو مكان وعلى قدر الإنتاج يكون المقابل.

\section{الإجراءات المننجية للبحث :}

$$
\text { أولاً: نوع البحث : }
$$

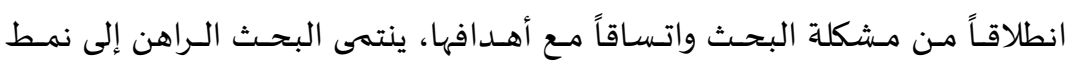

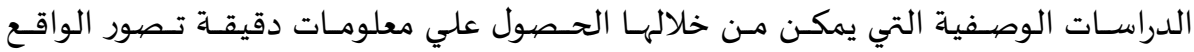

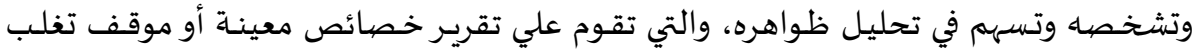

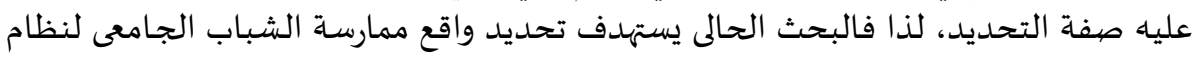

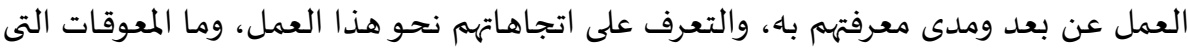

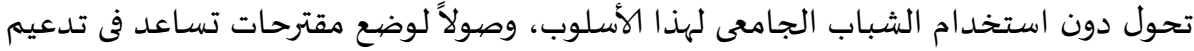


ثانيا: المنهج المستخدم.

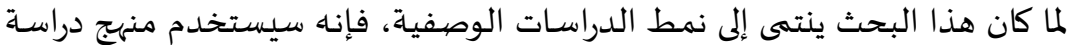

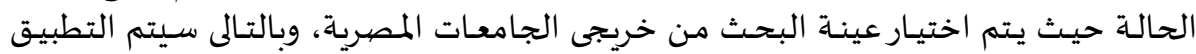

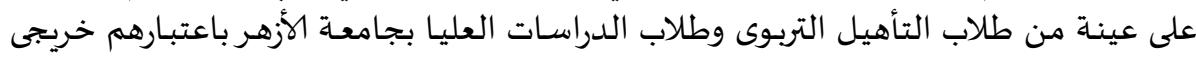

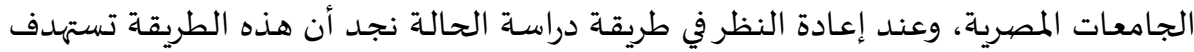

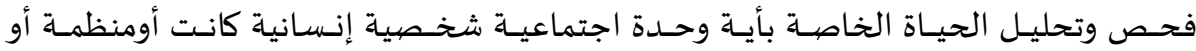

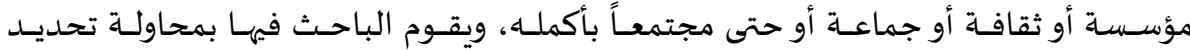

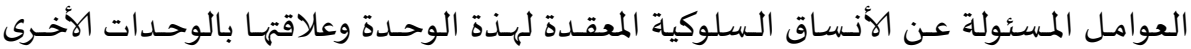
المحيطة بها.

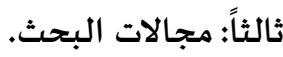

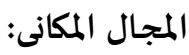

مراكز التأهيـل التربـوى بكليـة التربيـة جامعـة الأزهـر بالقـاهرة، وطلاب الدراســات العليـا بكليـة التربية بالقاهرة بجامعال الأزهر.

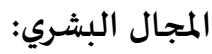

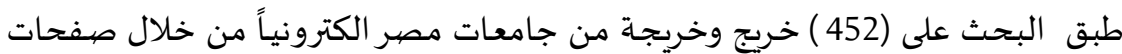

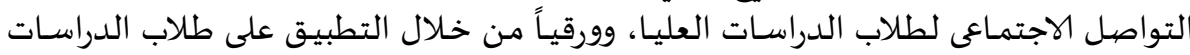
العليا وطلاب التأهيل التربوى بكلية التربية جامعة الزٔزهر فرعى( القاهرة والجيزة). المجال الزمنى :طبق البحث بداية من 2020/10/25 إلي 2020/11/15م .

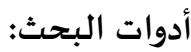

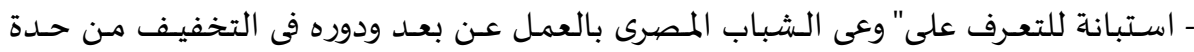
البطالة" مطبقة على خريجى الجامعات المصرية. - دليل مقابلة شبه مقننة للخبراء والعاملين في مجال العمل عن بعد. - مقابلات مفتوحة مع بعض العاملين في مجال العمل عن بعد.

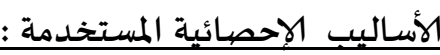

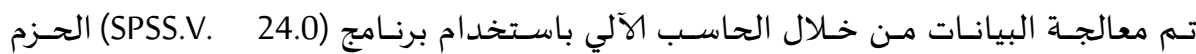

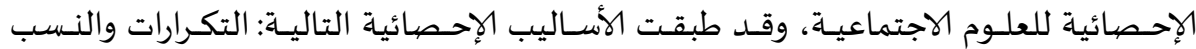

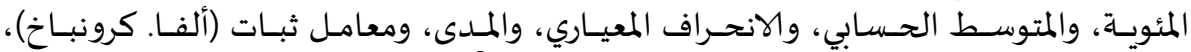

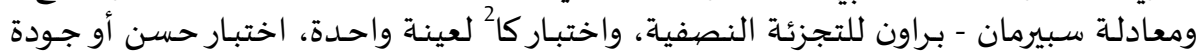

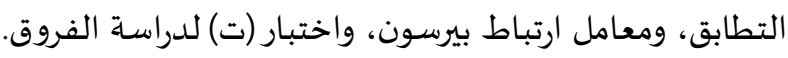




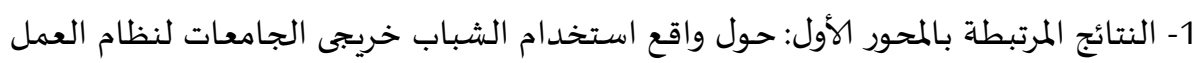
عن بعد بالمجتمع المصرى وتم التعرف عليه من خلالمال الأبعاد التالية هما:

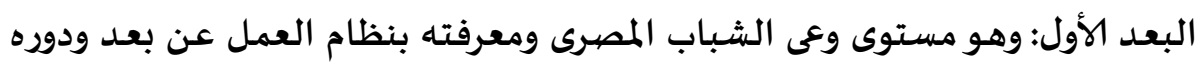
فى التخفيف من حدة البطالة.

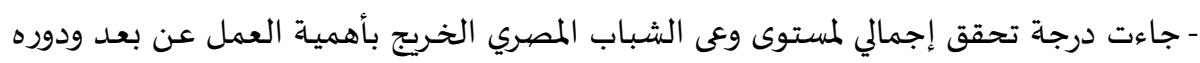

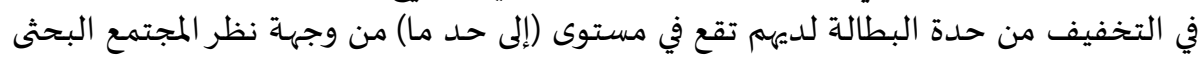

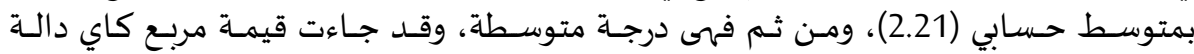

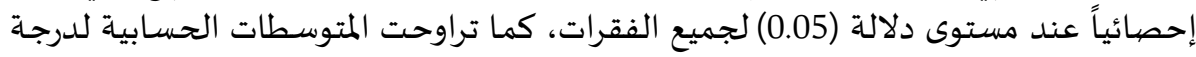
التحقق على مستوى الفقرات في الفترة من (0) (1.40) إلى (2.87).

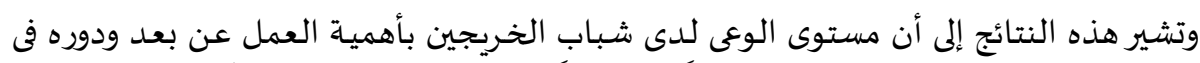

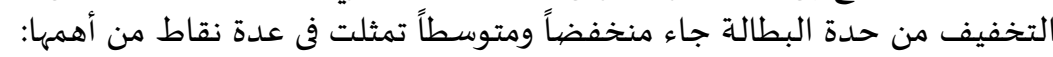

- أجهل المجالات التي يمكن ممارسـة العمل فهيها عن بعـد، بمتوسط حسابي (2.01)،

وانحراف معياري (0.74).

- ـ ـ أتابع المواقع التي تنشر وظائف عن بعد، بمتوسط حسابي (1.88)، وانحراف معياري

- ليس لـدى معلومـات عن العائد المادي للعمل عـن بعـد، بمتوسط حسابي

وانحراف معياري (0.77).

- - ل لـدى خبرة في ممارسـة العمل عن بعد، بمتوسط حسابي (1.71)، وانحراف معيـاري

- معلوماتي عن نظام العمل عن بعد غير كافيـة، بمتوسط حسابي (1.69)، وانحراف

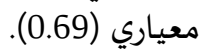

- أحتـاج لمعرفـة كيفيـة العمل عـن بعـد، بمتوسط حسابي (1.58)، وانحــراف معيـاري

- أحتـاج لمعرفـة مزايـا وسـلبيات العمل عـن بعـد، بمتوسـط حسابي (1.46)، وانحـراف

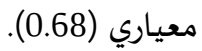

- أحتـاج لفهم متطلبـات هـذا النوع مـن العمل، بمتوسـط حسابي (1.40)، وانحـراف

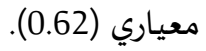


- أعرف أن هناك شركات تحتاج عاملين عن بعد، بمتوسط حسابي (2.31)، وانحراف

$$
\text { معياري (0.85). }
$$

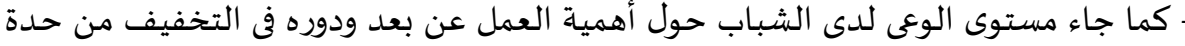

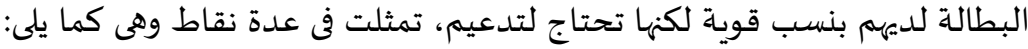

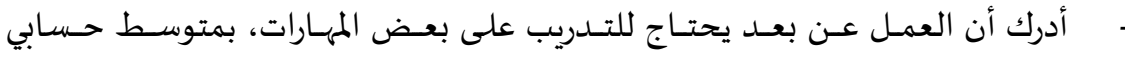
(2.87) ، وانحراف معياري (0.39).

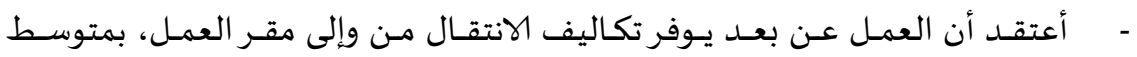
حسابي (2.74)، وانحراف معياري (0.54).

- أرى أن التسبويق الإلكتروني نـوع مـن العمـل عـن بعـد، بمتوسـط حسـابي (2.69)، وانحراف معياري (0.63). (أن آنسوني

أعتقد أن العمل عن بعـد مضيعة للوقت دون استفادة، بمتوسط حسابي (2.61)،

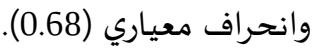

- أعلم أن العمل عن بعد يساعد على التخفيف من مشكلة البطالة، بمتوسط حسابي

(2.59)، وانحراف معياري (0.66).

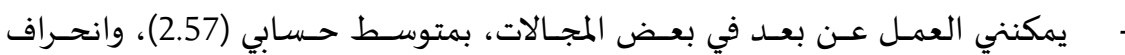

$$
\text { معياري (0.66). }
$$

- أرى أن العمل عـن بعـد يساعد على سـرعة إنجـاز المهام، بمتوسـط حسابي (2.56)،

وانحراف معياري (0.62).

- سـمعت مـن قبـل عـن نظـام العمل عـن بعـد، بمتوسـط حسابي (2.51)، وانحـراف

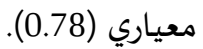

- أرى أن العمل عـن بعـد يساعد في تحقيق التـوازن بين المتطلبـات الأسـرية والعملـ،

بمتوسط حسابي (2.49)، وانحراف معياري (0.71).

- أرى أن العمل عن بعد أكبر من قدراتي، بمتوسط حسابي (2.46)، وانحراف معياري

- أعـرف بعض الأشخخاص الذذين مارسـوا العمل عـن بعـد، بمتوسـط حسابي (2.34)، وانحراف معياري (0.84).

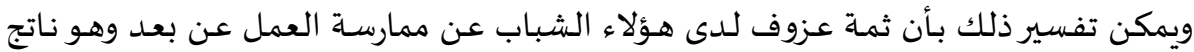

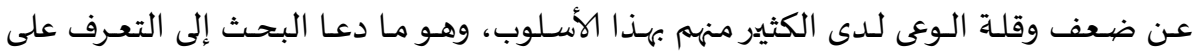


أسباب هذا العزوف، وتفسيره وإلى من ترجع هذه الأسباب، وهو ما يمكن توضيحها في محـور

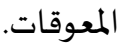

البعـد الثانى: وهو اتجاهـات الشباب نحـو تطبيق العمل عن بعـد للتخفيف من حـدة

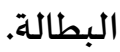

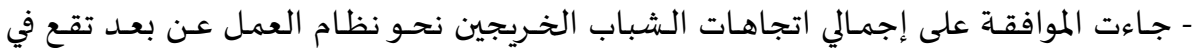

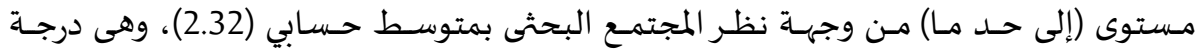

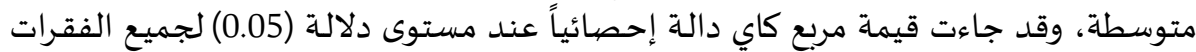

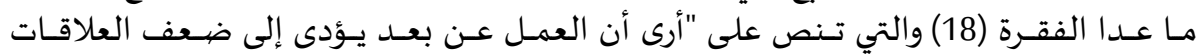

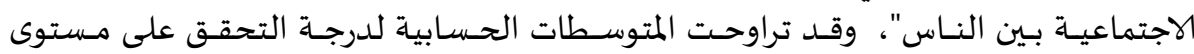
الفقرات في الفترة من (1.61) إلى (2.75).

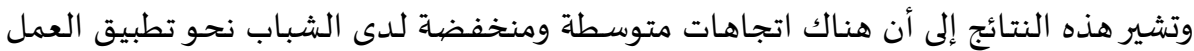
عن بعد للتخفيف من حدة البطالة، وهذه الاتجاهات آن التهات تمثلت في عدة نقاط من أهمها:

- أحتـاج لمـن يغيـر فكرتى الـسلبية عـن العمـل عـن بعـد، بمتوسـط حسابي (1.97)، وانحراف معياري (0.87).

- - أرى أن العمل عن بعد يؤدى إلى ضعف العلاقات الاجتماعية بين الناس، بمتوسط حسابي (1.94)، وانحراف معياري (0.80).

أرى أن هنـاك صـعوبة فى التعاقــ على فرصــة عمـل عـن بعـد، بمتوسـط حسابي (1.92)، وانحراف معياري (0.75).

سألت البعض عن ضهوابط العمل عن بعد التى تحفظ حقوقى، بمتوسط حسابي (1.61)، وانحراف معياري (0.81).

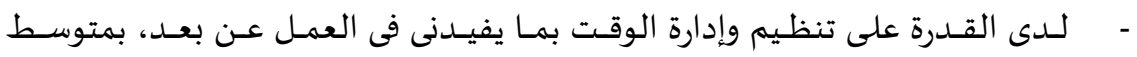
حسابي (2.33)، وانحراف معياري (0.70).

- أحتاج لمن يدعمنى في الحصول على فرصة عمل من المنزل، بمتوسط حسابي (2.30)، وانحراف معياري (0.82).

أبحث عن فرصارة عمل عن بعد تكون مناسبة لى، بمتوسط حسابي (2.29)، وانحراف

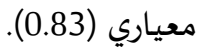
- أتساءل عن كيفية متابعتى فى العمل عن بعـد، بمتوسط حسابي (2.81))، وانحراف

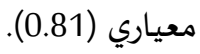
ـ ـ أعتقد أن العمل عـن بعـد يسـاعد على التراخى والكسل، بمتوسط حسابي (2.27)، وانحراف معياري (0.78). 
- أبحث عن المجالات التى تمارس عن بعد، بمتوسط حسابي (2.18)، وانحراف معياري

أرى أن العمل عن بعد لا يلبى طموحاتى، بمتوسط حسابي (2.17)، وانحراف معياري

كما جاءت اتجاهات الشباب نحو تطبيق العمل عن بعد للتحفيف من من حند حدة البطالة لديهم

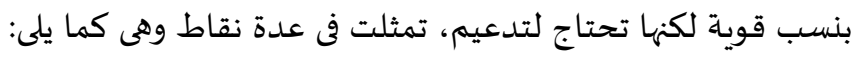

- أشجع أسلوب العمل عن بعد في ظل الظروف الحاليـة، بمتوسط حسابي (2.75)، وانحراف معياري (0.52).

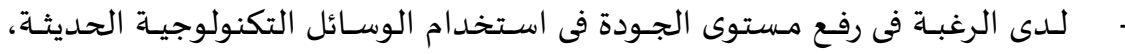
بمتوسط حسابي (2.65)، وانحراف معياري (0.64).

- أدرك أن العمل عن بعد يجعلنى أستثمر وقتى فيما يفيد، بمتوسط حسابي (2.61)،

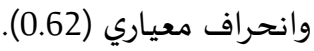

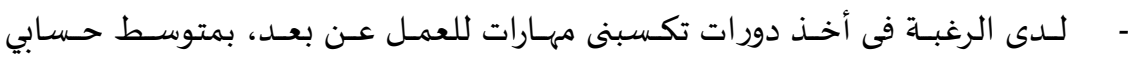

(2.55)، وانحراف معياري (0.68).

- لا أومن بالعمل عن بعد، بمتوسط حسابي (2.53)، وانحراف معياري (0.73).

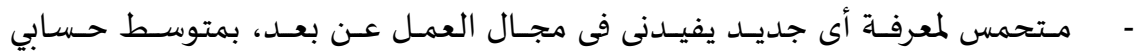

(2.52)، وانحراف معياري (0.71).

أسـعى للاسـتفادة مـن خببرات الـذين يعملـون عـن بعـد، بمتوسـط حسابي (2.51)،

وانحراف معياري (0.71).

ليس لـدى استعداد للعمل عـن بعـد، بمتوسـط حسابي (2.42)، وانحـراف معيـاري

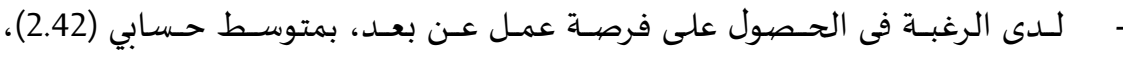
وانحراف معياري (0.77).

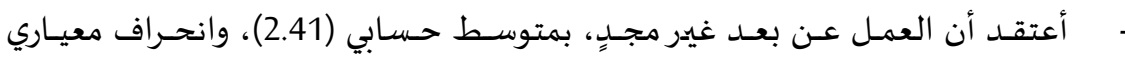

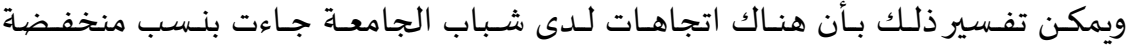

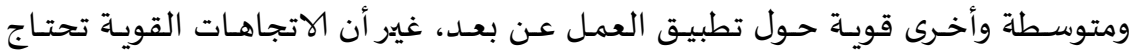

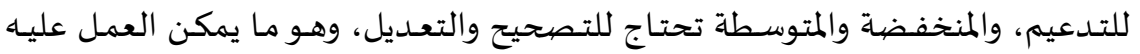

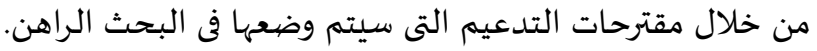


2- النتائج المرتبطة بالمحور الثانى: المعوقات التى تحول دون استخدام الشباب لنظام العمل

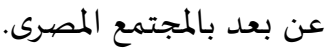

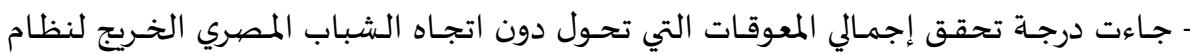

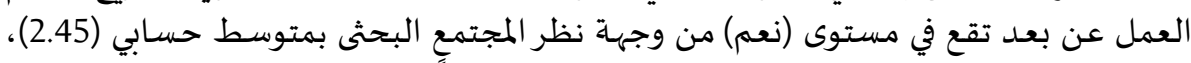

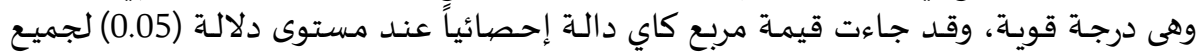

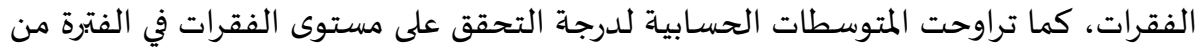
(2.67) (1.94) إلى ترات.

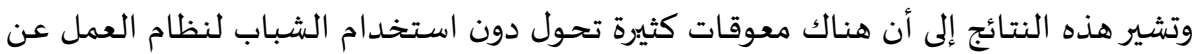

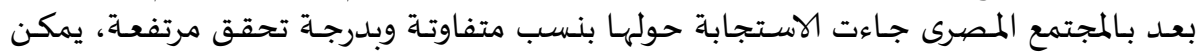

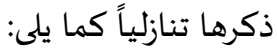

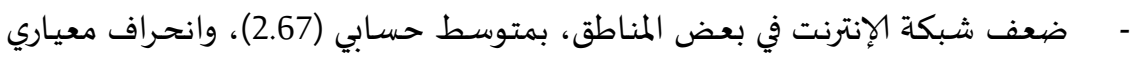

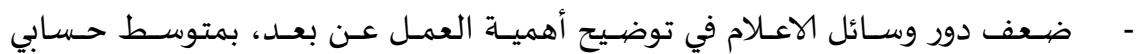
(2.66)، وانحراف معياري (0.56).

- الجعف دور الجامعة في نشرثقافة العمل عن بعد في ظل اقتصاد المعرفة، بمتوسط حسابي (2.65)، وانحراف معياري (0.58). قلـة وجـود عقـود ملزمـة بـين أطـراف العمـل عـن بعـد، بمتوسـط حسابي (2.64)، وانحراف معياري (0.57).

الافتقار إلى تجارب ناجحـة لنقل الخبرة في مجال العمل عن بعد، بمتوسط حسابي (2.59)، وانحراف معياري (0.61). - عـدم قيام الشركات بتـوفير معلومات كافيـة عن العمل عـن بعـد، بمتوسط حسابي (2.56)، وانحراف معياري (0.61). قلـة الـدورات التدريبيـة حـول العمل عـن بعـد، بمتوسـط حسابي (2.56)، وانحـراف

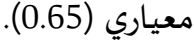
ضعف الدور الذي تقوم به الشركات في نشرثقافة العمل عن بعد، بمتوسط حسابي (2.53)، وانحراف معياري (0.60).

ضيعف التنسيق بين الشركات والجهات المعنية بنشر ثقافة العمل عن بعد، بمتوسط حسابي (2.53)، وانحراف معياري (0.61). 
عـدم ثقتي في الـشركات التي توظف عـن بعـد، بمتوسط حسابي (2.48)، وانحـراف

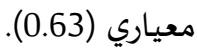

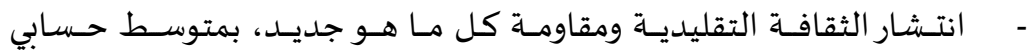
وانحراف معياري (0.67).

- صـعوبة الحصول على كل مـا هـو مطلـوب الكترونيـاً عـن هـذا الهـلوب، بمتوسـط حسابي (2.45)، وانحراف معياري (0.68).

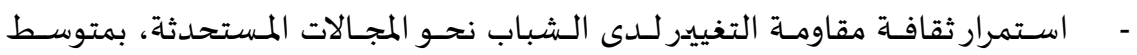
حسابي (2.43)، وانحراف معياري (0.64).

- صعوبة التواصل مع الأفكار التى تتناول أسلوب العمل عن بعد.، ، بمتوسط حسابي (2.42)، وانحراف معياري (0.65).

- عدم ثبات الدخل، بمتوسط حسابي (2.41)، وانحراف معياري (0.69). - أفتقر للكثير من المهارات اللازمة للعمل عن بعد، بمتوسط حسابي (2.38)، وانحراف

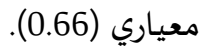

- عدم ثبات العمل، بمتوسط حسابي (2.38)، وانحراف معياري (0.71). - محدودية المجالات التي تمارس عن بعد، بمتوسط حسابي (2.37)، وانحراف معياري

- الخوف من الفشل، بمتوسط حسابي (2.34)، وانحراف معياري (0.78). - أهـتم بـالتوظيف الحكومي دون غيره، بمتوسـط حسابي (2.08)، وانحـــاف معيـاري

- عـدم قنـاعتي بأهميـة العمل عـن بعـد، بمتوسـط حسابي (1.94)، وانحـراف معيـاري

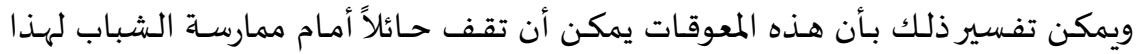

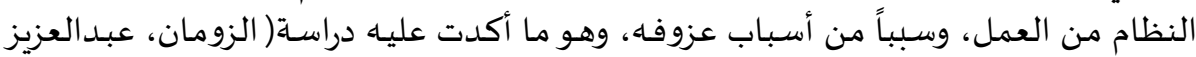

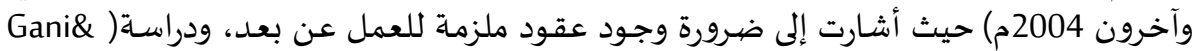

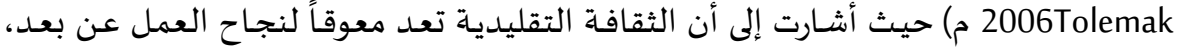

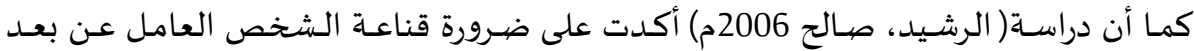

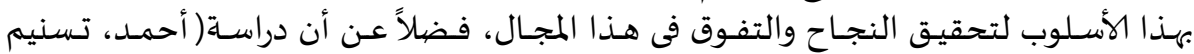

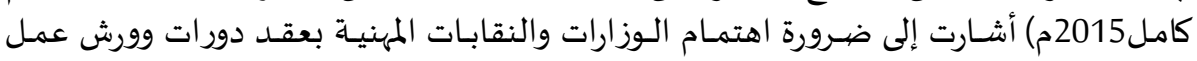

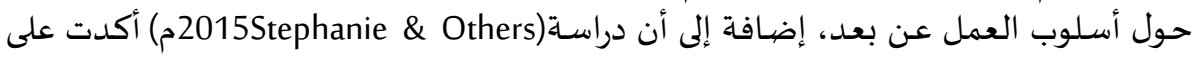

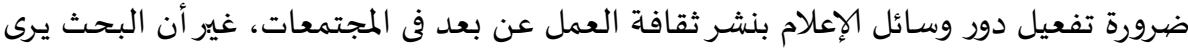




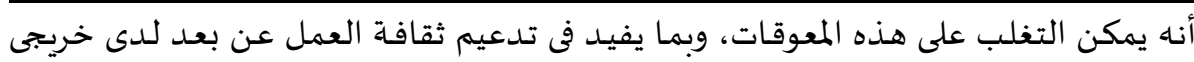

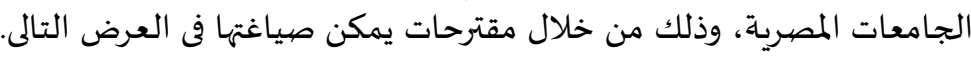

\section{مقترحات تدعيم ثقافة العمل عن بعد في ضوء نتائج البحث الميدانية:}

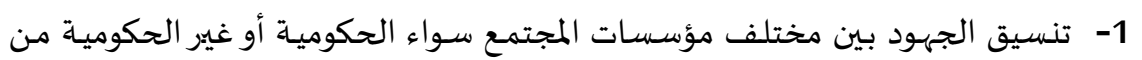

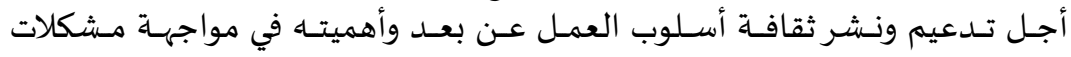
الشباب الحيوية والتي منها مشكلة البطالة.

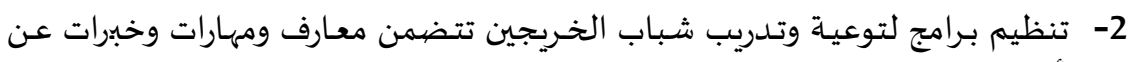

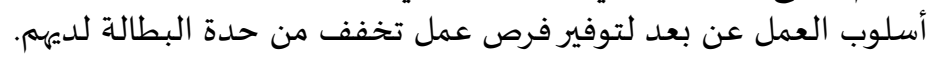

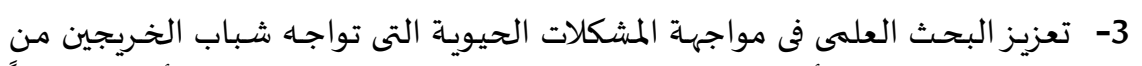

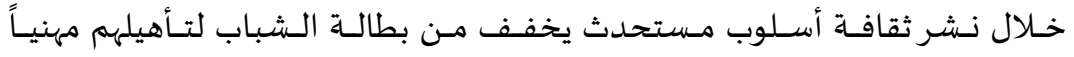

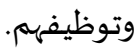

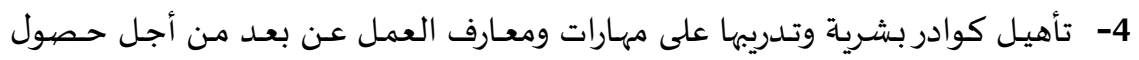

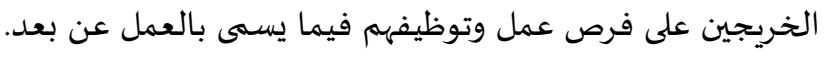

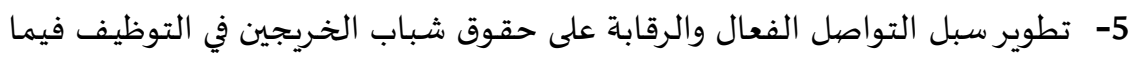

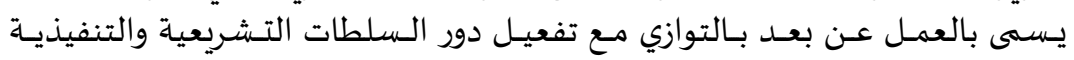
والقضائية. 6- اتخـاذ كل الإجراءات اللازمة للدعم شباب الخريجين للحصيول على فرص للتوظيف من خلال هذا الأسلوب وغيره.

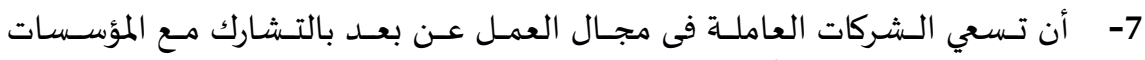

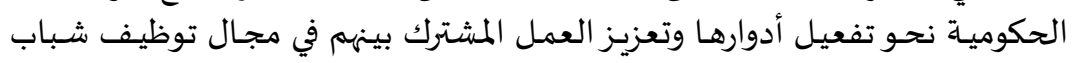
الخريجين فيما يسمى بالعمل عن بعديل أدوارونا وتعزبز العمل

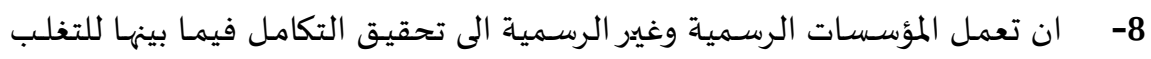
على مشكلة البطالة لدي الخريجين أو التخفيف من حدنها.

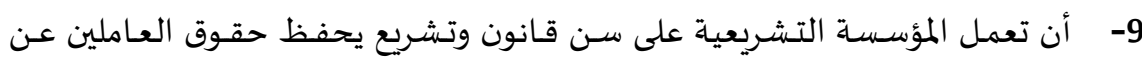
بعد وأصحاب العمل بما يضمن نجاح العمل عن بعد وضمان المان استمراريته.

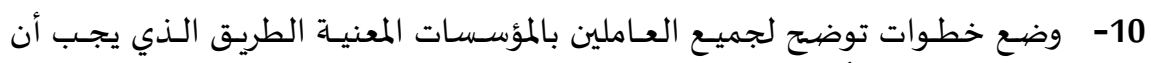

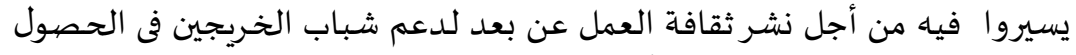
على فرصة عمل من خلال هذا الأسلوب.

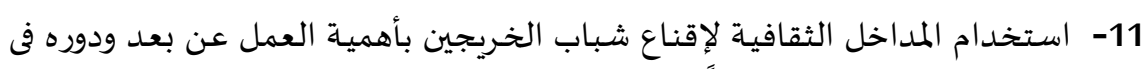
توفير فرص عمل لهم تخفيفاً لما يواجهونه من بطالئ.

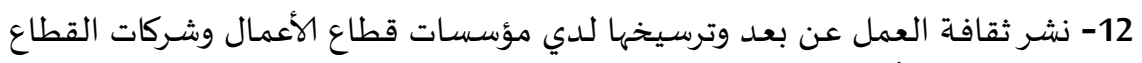

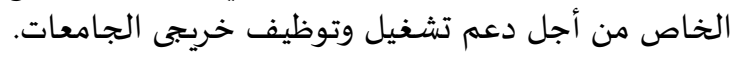




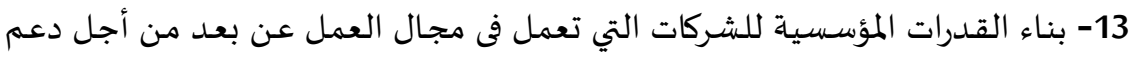

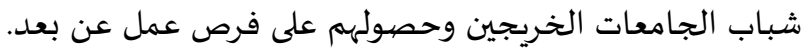

14- سن التشريعات والقوانين التي تنظم العمل عن بعد وتضمن حقوق كل الأطراف.

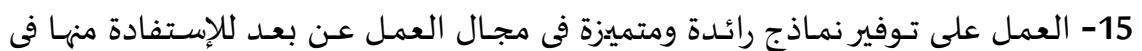

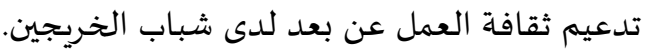

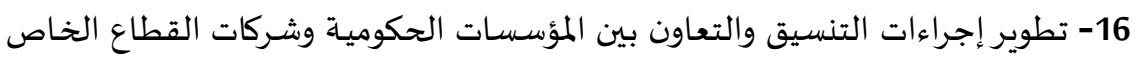
لدعم توظيف وتشغيل شباب الخريجين.

17- العمل على تطوير البنية المعرفية والمهارية والوجدانية الخاصية بالعمل عن بعد من

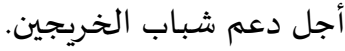

18- دعم مبـادرات بعض المؤسسـات الرسـمية الخاصـة بتـدريب الشباب على تكنولوجيـيا

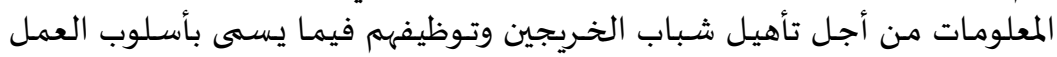

عن بعد.

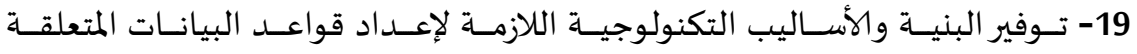

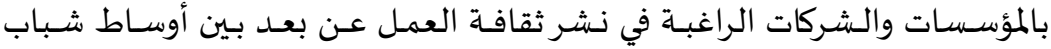

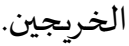

20- إعـداد قواعـد بيانـات الكترونيـة عـن الـشباب الخـريجين والبرامج التدريبيـة اللازمـة

للعمل عن بعد بالمجتمع المصرى.

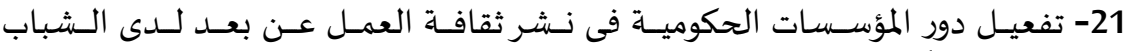

وخصوصاً المؤسسات التعليمية والإعلامية والتثقيفية.

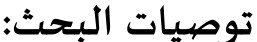

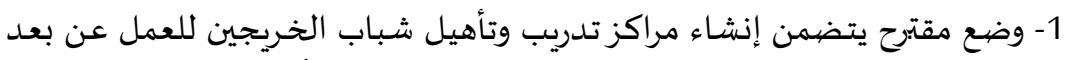

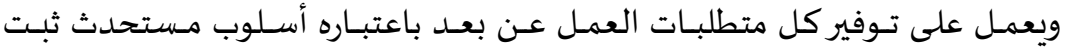

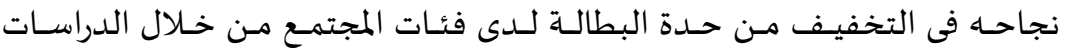

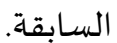

2- وضع آلية لعمل تلك المراكز ووضع مجموعة من الضمانات الكماتلازمة لتفعيل دورها

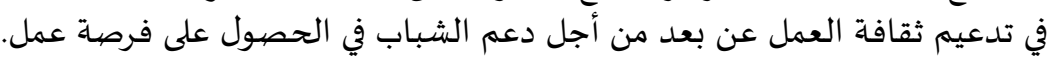

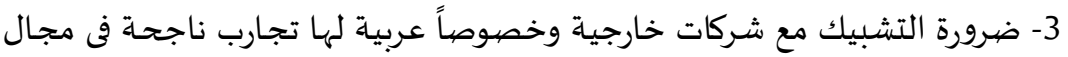

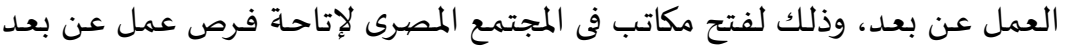

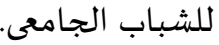




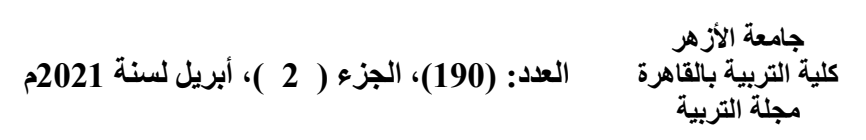

\section{مراجع البحث}

أولاً: المراجع العربية.

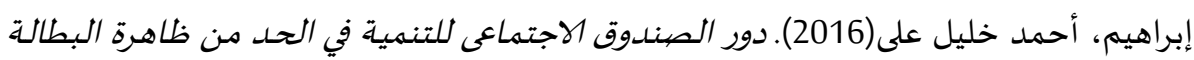

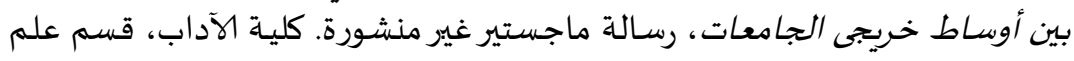
الاجتماع، جامعة المنصورة.

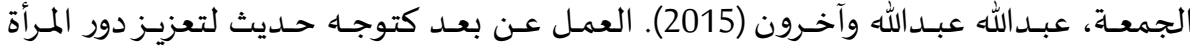

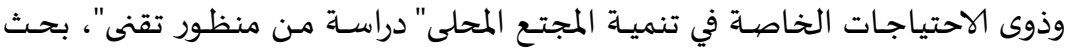

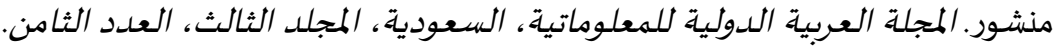
الجهاز المركزى للتعبئـة العامـة والاحصاء (مـارس 2019). الكتاب السنوى الاحصيائى مصرفى

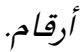

الجهاز المركزى للتعبئـة العامـة والاحصياء(أبريل 2020م).تقريرحسول البطالة فى ظل تـداعيات

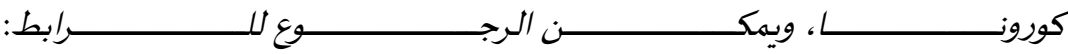

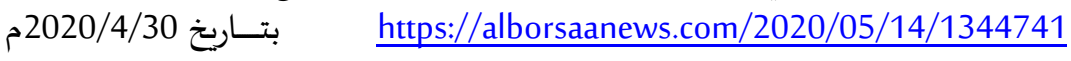
الساعة 5م.

الجهاز المركزى للتعبئة العامة والاحصاء(2019).تقريرحول نسب الخريجين وأعداد المتعطلين

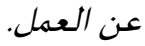
الرشيد، صالح بن سليمان (2007). إطار منهجى لتشغيل المرأة السعودية في ظل تبنى خيارات العمل عن بعد. صندوق تنمية الموارد البشرية.

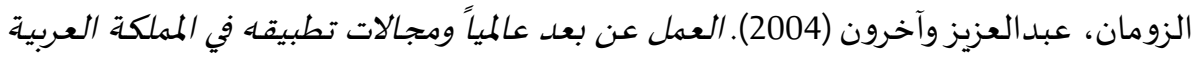

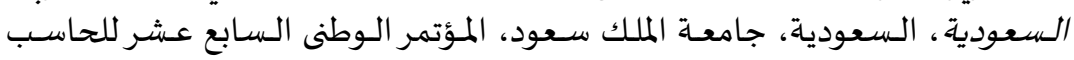

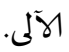

السيد، نعمـة أمين (2016).الأثارالاقتصادية والاجتماعية لبطالة خريجى التعليم العالى في

مصروسياسات مواجهتها، رسالة ماجستير غير منشورة. كلية التجارة، جامعة بنها.

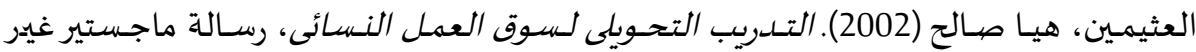
منشورة. كلية التربية، جامعة أم القرى بالمملكة العربية السعودية.

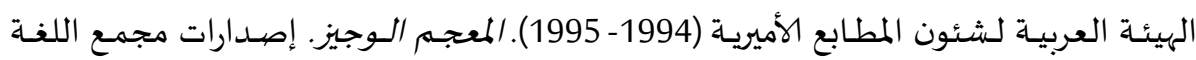

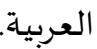

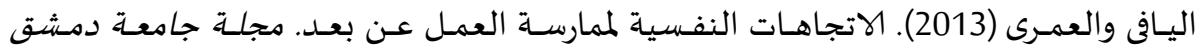
للعلوم الاقتصيادية والقانونية، سوريا، 2 (29).

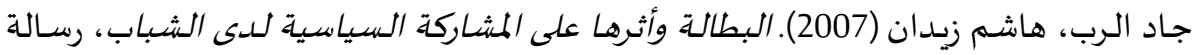

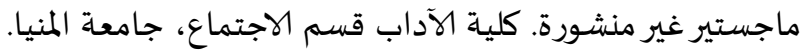




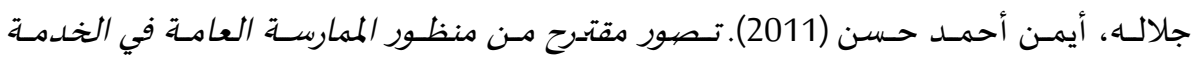

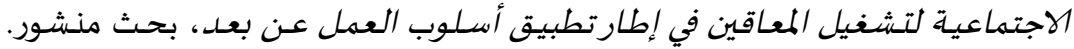

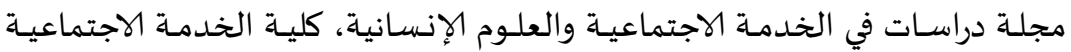

بحلوان، 31) (7).

حسن، عبدالباسط محمد (2000). التنمية الاجتماعية. مكتبة وهبة.

حزام، منى عطيـة خليـل (2011). التخطيط الاجتماعى في المجتمع المعاصرر. المكتب الجـامعى

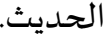

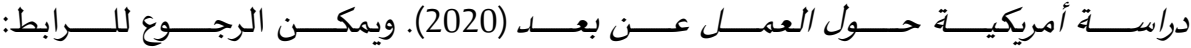
2020/6/25 بتاريخ https://www.awalan.com/

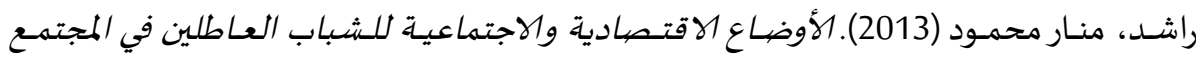

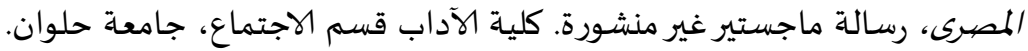

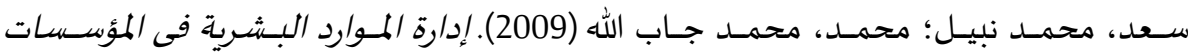

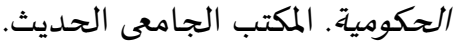

على، ماهر أبو المعاطى (2010).الاتجاهات الحديثة فى التخطيط الاجتماعى. المكتب الجـامعى

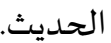

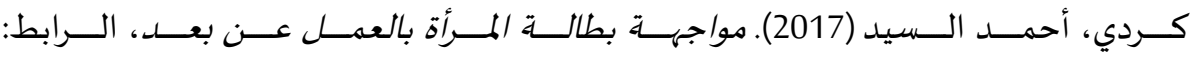
http://kenanaonline.com/users/ahmedkordy/posts/375588 2017/11/15م السـاعة 3:30عصرا.

محمد، محمد مصطفى (2017). البطالة وعلاقتها بالجريمة في المجتمع المصري، دراسة ميدانية المانية

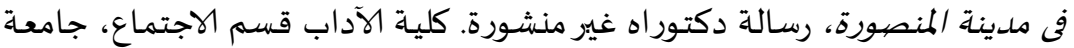
المنصورة.

محمد، سميرة كامل (1998). التخطيط الاجتماعى" مدخل إلى القرن الواحد والعشرين". المكتب

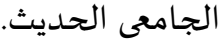

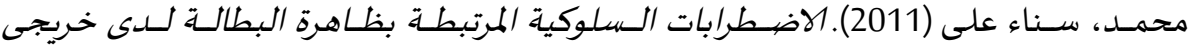

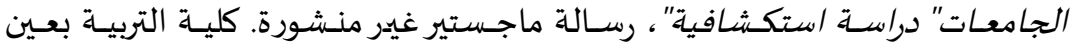
شمس .

محمود، كوثر ربحى (2010). المشكلات المترتبة على بطالة الشباب خريجى الجامعات الفلسطينية

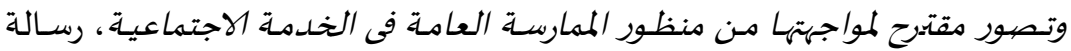
ماجستير غير منشورة. كلية الخدمة الاجتماعية قسم المجالات، جامعاة حلوان. مركز الإنتاج الإعلامى بجامعة الملك عبدالعزيز (1428). نحو مجتمع المعرفة - العمل عن بعد. مصطفى، مصططفى محمود (2006). التغير القيهى لدى المتعطلين من شباب الخريجين، رسالة

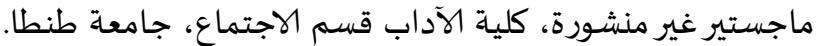




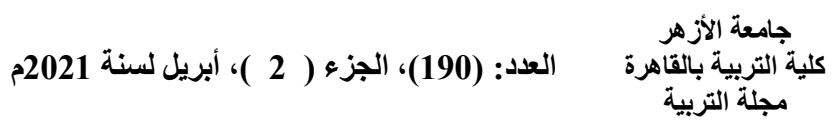

موقع العربى الجديد: تكنولوجيا العمل عن بعـد (2017). الرابط: WWW Alaraby.com uk بتاريخ 2017/10/25م الساعة 4 مساءاً. ثانيا: المراجع العربية مترجمة

Ibrahim, A. K. A. (2016). The role of the social fund in reducing unemployment among university graduates, unpublished master's thesis. Faculty of Arts, Department of Sociology, Mansoura University.

Friday, A. A. et al. (2015). Remote work as a modern approach to enhancing the role of women and people with special needs in the development of the local community". A study from a technical perspective", published research. The Arab International Journal of Informatics, Saudi Arabia, 2.(8)

Central Agency for Public Mobilization and Statistics (March 2019). Statistical Yearbook Egypt in Numbers.

Central Agency for Public Mobilization and Statistics (April 2020 AD). A report on unemployment in light of the repercussions of Corona, retrieved from: https://alborsaanews.com/2020/05/14/1344741 on $4 / 30 / 2020$ at $5 \mathrm{pm}$.

Central Agency for Public Mobilization and Statistics (2019). A report on the percentage of graduates and the number of unemployed.

Al-Rasheed, S. S. (2007). A systematic framework for the employment of Saudi women in light of the adoption of remote work options. Human Resources Development Fund.

Al-Zoman, A. et al. (2004). Remote work globally and its fields of application in the Kingdom of Saudi Arabia, Saudi Arabia, King Saud University, the Seventeenth National Conference on Computer.

El-Sayed, N. A. (2016). The economic and social effects of unemployment of higher education graduates in Egypt and the policies to confront it, unpublished master's thesis. Banha University Faculty of Commerce.

Al-Othaimeen, H. S. (2002). Transformative training for the women's labor market, unpublished master's thesis. College of Education, Umm AlQura University, Kingdom of Saudi Arabia.

The Arab Authority for Emiri Press Affairs (1994 - 1995). Brief dictionary. Arabic Language Academy Publications.

Al Yafi \& Al Omari (2013). Psychological trends of remote work practice. Damascus University Journal of Economic and Legal Sciences, Syria, 2.(29)

Gad El-Rub, H. Z. (2007). Unemployment and its impact on political participation among young people, unpublished master's thesis. Faculty of Arts, Department of Sociology, Minia University. 
Galala, A. A. H. (2011). A proposed perception from the perspective of general practice in social work for the employment of the disabled within the framework of the application of the remote work method. Journal of Studies in Social Work and Human Sciences, Faculty of Social Work in Helwan, 31.(7)

Hassan, A. M. (2000). Social development. Wahba Library.

Khuzam, M. A. K. (2011). Social planning in contemporary society. Modern University Office.

An American study on remote work (2020). Retrieved form: https://www.awalan.com/ on 25/6/2020 AD.

Rashid, M. M. (2013). Economic and social conditions of unemployed youth in Egyptian society, unpublished master's thesis. Faculty of Arts, Department of Sociology, Helwan University.

Saad, M. N.; Muhammad, M. J. (2009). Human resource management in government institutions. Modern university office.

Ali, M. A. (2010). Recent trends in social planning. Modern University Office.

Kurdi, A. E. (2017). Confronting women's unemployment by working remotely. Retrieved from: http://kenanaonline.com/users/ahmedkordy/posts/375588 on $11 / 15 / 2017$ at $3: 30 \mathrm{pm}$.

Muhammad, M. M. (2017). Unemployment and its relationship to crime in the Egyptian society, a field study in the city of Mansoura, unpublished PhD thesis. Faculty of Arts, Department of Sociology, Mansoura University.

Mohamed, S. K. (1998). Social planning: an Introduction to the Twenty-first Century. Modern University Office.

Muhammad, S. A. (2011). Behavioral disorders associated with unemployment among university graduates, an "exploratory study", an unpublished master's thesis. Faculty of Education, Ain Shams.

Mahmoud, K. R. (2010). Problems arising from the unemployment of young graduates of Palestinian universities and a proposal to confront them from the perspective of general practice in social work, unpublished master's thesis. Faculty of Social Work, Department of Fields, Helwan University .

Media Production Center at King Abdulaziz University (1428). Towards a knowledge society - remote work.

Mustafa, M. M. (2006). Value change among the unemployed young graduates, unpublished master's thesis, Faculty of Arts, Department of Sociology, Tanta University.

Al-Araby Al-Jadeed: Remote Work Technology (2017). Retrieved from: WWW Alaraby.com uk on 10/25/2017 at 4 pm. 
Haddon, I. (1999). Annroaches

to

understanding teleworking. Telektronikk, 95(4), 29-38.

Hynes, M. (2014). Telework isn't working: A nolicy review. The Economic and Social Review, 45(4, Winter), 579-602.

Nicholas. A. J. (2014). Management and telework. In Encvclonedia of business analytics and optimization (pp. 1435-1445). IGI Global.

Smith, S. A.. Patmos. A.. \& Pitts. M. J. (2018). Communication and teleworking: A studv of communication channel satisfaction. nersonalitv. and iob satisfaction for teleworking emnloyees. International Journal of Business Communication, 55(1), 44-68.

Takala, J. (1999). Global estimates of fatal occupational accidents. Epidemiology, 640-646.

Van Der Meulen. D. (2010). Modeling the choice of telework freauencv and its effects on nroductivitv and work/life halance (Doctoral dissertation. Master Dissertation. RSM Erasmus University, Rotterdam). 